\title{
Warm-white luminescence of Dy3+ and Sm3+ co- doped NaSrPO4 phosphors through energy transfer between Dy3+ and Sm3+ ions
}

\section{Wen Yan}

Chengdu University of Technology

Junhan Li

Panzhihua University

Wentao Zhang ( $\square$ zhangwentao2012@mail.cdut.edu.cn )

Chengdu University of Technology https://orcid.org/0000-0002-9924-9513

Xi Gao

Chengdu University of Technology

Peicong Zhang

Chengdu University of Technology

\section{Research Article}

Keywords: NaSrPO4, Rare earth, Sol-gel method, Warm white emission, Energy transfer

Posted Date: February 11th, 2021

DOI: https://doi.org/10.21203/rs.3.rs-217689/v1

License: (c) (1) This work is licensed under a Creative Commons Attribution 4.0 International License. Read Full License 


\title{
Warm-white luminescence of $\mathrm{Dy}^{3+}$ and $\mathrm{Sm}^{3+}$ co-doped $\mathrm{NaSrPO}_{4}$ phosphors through energy transfer between $\mathrm{Dy}^{3+}$ and $\mathrm{Sm}^{3+}$ ions
}

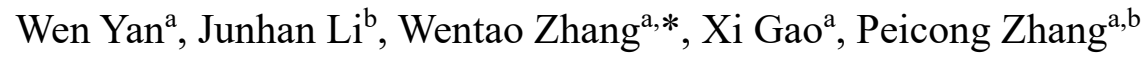 \\ ${ }^{a}$ College of Materials and Chemistry \& Chemical Engineering, Chengdu University \\ of Technology, Chengdu 610059, China \\ ${ }^{\mathrm{b}}$ Sichuan Research Center of Vanadium and Titanium Industry Development, \\ Panzhihua University, Panzhihua 617000, China \\ * Corresponding author: College of Materials and Chemistry \& Chemical \\ Engineering, Chengdu University of Technology, Chengdu 610059, China. E-mail: \\ zhangwentao2012@mail.cdut.edu.cn (W. Zhang).
}

\begin{abstract}
Series of white-light-emitting $\mathrm{NaSrPO}_{4}: \mathrm{Dy}^{3+}$ phosphors were synthesized via a sol-gel method. Small amounts of $\mathrm{Sm}^{3+}$ ions were co-doped into the phosphors to enhance their luminescence. The effects of $\mathrm{Dy}^{3+} / \mathrm{Sm}^{3+}$ co-doping concentrations and synthesis temperature on the phosphors' structures and luminescence properties were investigated. The results of X-ray diffraction confirmed that the characteristic diffraction peaks of the phosphors were in accord with those of the standard $\mathrm{NaSrPO}_{4}$ structure. Energy dispersive spectroscopy indicated that the $\mathrm{NaSrPO}_{4}: \mathrm{Dy}^{3+}$ samples were prepared with stoichiometric ratios of elements. Under ultraviolet light excitation of $348 \mathrm{~nm}$, the $\mathrm{NaSrPO}_{4}: \mathrm{Dy}^{3+}$ phosphors emitted a white light which was composed of two emission peaks at $484 \mathrm{~nm}$ (blue) and $577 \mathrm{~nm}$ (yellow) corresponding to the magnetic dipole transition ${ }^{4} \mathrm{~F}_{9 / 2} \rightarrow{ }^{6} \mathrm{H}_{15 / 2}$ and electronic dipole transition ${ }^{4} \mathrm{~F}_{9 / 2} \rightarrow{ }^{6} \mathrm{H}_{13 / 2}$ of $\mathrm{Dy}^{3+}$ ions, respectively. Based on $\mathrm{Sm}^{3+}$ co-doping, a characteristic red emission at $602 \mathrm{~nm}$ arose and a warm-white light containing a lower
\end{abstract}


$C C T$ value was obtained. Besides, the luminescence lifetime of $\mathrm{Dy}^{3+}$ decreased while that of $\mathrm{Sm}^{3+}$ increased as dosages of $\mathrm{Sm}^{3+}$ were added, indicating efficient energy transfer from $\mathrm{Dy}^{3+}$ to $\mathrm{Sm}^{3+}$ happened. Therefore, $\mathrm{NaSrPO} 4: \mathrm{Dy}^{3+}, \mathrm{Sm}^{3+}$ phosphors are promising candidates for application in warm-white light-emitting diodes.

Keywords: $\mathrm{NaSrPO}_{4}$; Rare earth; Sol-gel method; Warm white emission; Energy transfer.

\section{Introduction}

As environmental pollution and the energy crisis have become increasingly serious, white-light-emitting diodes (w-LEDs) are being increasingly utilized in illuminating systems and display applications [1-4], by virtue of their environmental friendliness, energy savings, and high energy efficiency [5-7]. Typically, widespread w-LEDs are composed of a blue InGaN chip and a yellow $\mathrm{Y}_{3} \mathrm{Al}_{5} \mathrm{O}_{12}: \mathrm{Ce}^{3+}$ (YAG:Ce) phosphor [8-11]. There are shortcomings to this combination, just as highly correlated color temperature $(C C T>5000 \mathrm{~K})$ and low color rendering index $(C R I<80)$, since lack of a red emission component [12-15]. Additionally, some researchers have made novel w-LEDs with an ultraviolet (UV) LED chip and tri-color (RGB) phosphors to realize white light. However, this method has several disadvantages related to color ratio control, color reabsorption, and luminous efficiency [16,17]. Therefore, a novel single-component phosphor that produces excellent white light emission under UVlight excitation is urgently needed $[18,19]$.

In phosphors, rare earth $\mathrm{Dy}^{3+}$ ions possess two characteristic emission peaks: a blue peak at about $480 \mathrm{~nm}\left({ }^{4} \mathrm{~F}_{9 / 2} \rightarrow{ }^{6} \mathrm{H}_{15 / 2}\right)$ and a yellow one at about $580 \mathrm{~nm}\left({ }^{4} \mathrm{~F}_{9 / 2} \rightarrow\right.$ $\left.{ }^{6} \mathrm{H}_{13 / 2}\right)[20,21]$. White light is supposed to be achieved by uniting with blue and yellow emissions for w-LEDs applications [22-24]. Recently, numerous phosphors have been reported with admirable luminescence properties, such as 
$\mathrm{Na}_{3} \mathrm{MgZr}\left(\mathrm{PO}_{4}\right)_{3}: \mathrm{Dy}^{3+}$ [25], $\mathrm{Ba}_{3} \mathrm{Y}\left(\mathrm{PO}_{4}\right)_{3}: \mathrm{Dy}^{3+}$ [26], and $\mathrm{Ba} 3 \mathrm{La}\left(\mathrm{PO}_{4}\right)_{3}: \mathrm{Dy}^{3+}$ [27].

However, for the shortage of a red ingredient, the white emission of these $\mathrm{Dy}^{3+}$-doped phosphors have the drawbacks of low $C R I$ and high $C C T$ values. This is similar to using the combination of an InGaN chip with a YAG:Ce phosphor. In order to ameliorate these defects, red-emitting center $\mathrm{Sm}^{3+}$ ions can be introduced into $\mathrm{Dy}^{3+}-$ doped phosphors as they have a forceful emission peak relatively at $602 \mathrm{~nm}$ $\left({ }^{4} \mathrm{G}_{5 / 2} \rightarrow{ }^{6} \mathrm{H}_{7 / 2}\right)$ that can improve the luminescence properties $(C R I$ and $C C T)$ of the white emission of $\mathrm{Dy}^{3+}[28]$. By adjusting the ratio of the $\mathrm{Dy}^{3+}$ to $\mathrm{Sm}^{3+}$ concentration, excellent white light emissions, especially warm white, can be achieved. Phosphates are extensively utilized as phosphor hosts for their low synthesis temperatures and good chemical and thermal stability, including $\mathrm{Ca}_{2} \mathrm{Sr}\left(\mathrm{PO}_{4}\right)_{2}: \mathrm{Dy}^{3+}[29], \mathrm{LiCaPO}_{4}: \mathrm{Ce}$ [30], and $\mathrm{YPO}_{4}: \mathrm{Dy}^{3+} \backslash \mathrm{Eu}^{3+} \backslash \mathrm{Tb}^{3+}[31]$. Wet chemical methods can provide low synthesis temperatures, good crystal structures, and excellent luminescence properties. However, there has been little research on its structure or the preparation of rare-earth-doped $\mathrm{NaSrPO}_{4}$ by wet chemical methods [32-34], especially in $\mathrm{Dy}^{3+}$ doped $\mathrm{NaSrPO}_{4}$ white-emitting phosphors [35].

In this paper, $\mathrm{NaSrPO}_{4}: \mathrm{Dy}^{3+}, \mathrm{Sm}^{3+}$ phosphors were prepared using a sol-gel method and white light was expected to be obtained from their blue and yellow emissions. $\mathrm{Sm}^{3+}$ co-doping would adequately ameliorate the $\mathrm{CRI}$ and $C C T$ values of white light emission. The impacts of $\mathrm{Dy}^{3+} / \mathrm{Sm}^{3+}$ co-doping concentration and synthesis temperature on the structure and white light emission of $\mathrm{NaSrPO}_{4}: \mathrm{Dy}^{3+}$ samples were investigated. The results provide a reference for research into other white-lightemitting phosphors.

\section{Experimental}

All NaSrPO $4: \mathrm{Dy}^{3+}, \mathrm{Sm}^{3+}$ specimens were synthesized through a sol-gel method. The 
starting materials $\mathrm{CH}_{3} \mathrm{COONa}, \mathrm{Sr}\left(\mathrm{NO}_{3}\right)_{2}, \mathrm{NH}_{4} \mathrm{H}_{2} \mathrm{PO}_{4}, \mathrm{C}_{6} \mathrm{H}_{8} \mathrm{O}_{7}, \mathrm{Dy}_{2} \mathrm{O}_{3}$, and $\mathrm{Sm}_{2} \mathrm{O}_{3}$ were highly purified. The doping concentrations of $\mathrm{Dy}^{3+}$ were controlled within $0.5-5$ mol\%, while that of $\mathrm{Sm}^{3+}$ were regulated as $1-3 \mathrm{~mol} \%$ (relative to the molar amount of $\mathrm{Sr}^{2+}$ ). All raw materials were weighed out with stoichiometric ratios. First, a certain amount of $\mathrm{Dy}_{2} \mathrm{O}_{3}$ and $\mathrm{Sm}_{2} \mathrm{O}_{3}$ were dissolved in nitric acid to produce a nitrate solution, while suitable $\mathrm{CH}_{3} \mathrm{COONa}, \mathrm{Sr}\left(\mathrm{NO}_{3}\right)_{2}$, and $\mathrm{NH}_{4} \mathrm{H}_{2} \mathrm{PO}_{4}$ were added to a conical flask containing distilled water. Afterward, an appropriate amount of citric acid was drizzled into the above solution to form a stable system. The system was stirred fully by vigorous magnetic stirring at $70{ }^{\circ} \mathrm{C}$ for $2.5 \mathrm{~h}$ to form a transparent sol and heated by an air circulation oven at $80{ }^{\circ} \mathrm{C}$ for $36 \mathrm{~h}$ until a swelled yellow porous gel was formed. Ultimately, the sample was moved to a furnace and heated at 800 $1200{ }^{\circ} \mathrm{C}$ for $3 \mathrm{~h}$. The as-prepared phosphors were obtained when cooled naturally to room temperature $(R T)$.

The phase structure and purity of these as-prepared specimens were evaluated utilizing X-ray diffraction (XRD) on an X-ray diffractometer (DX-2700, Aolong Company, China) with $\mathrm{Cu} \mathrm{K}_{\alpha}$ radiation $(\lambda=1.5406 \AA)$ and a $2 \theta$ scanning speed of $5 \%$ min. The photoluminescence (PL) and lifetime measurements were carried out by a fluorescence spectrophotometer with excitation by a $150 \mathrm{~W}$ Xe lamp (F-4600, Hitachi, Japan). The quantum efficiency of as-prepared phosphors was acquired by a Quantum Efficiency Measurement System (QEMS 2000, Labsphere, USA). The morphologies and elemental compositions of the synthesized powders were verified via JSM-7800F scanning electron microscopy (SEM; JEOL, Japan) with energy dispersive spectroscopy (EDS). The absorption spectrogram of relevant powders was monitored through a UV-Vis-NIR diffuse reflectance (DR) spectrophotometer (Cary 5000, Agilent Inc., USA). All the above characterization tests were proceeded at $R T$. 


\section{Results and discussion}

The XRD patterns of $\mathrm{NaSrPO}_{4}: \mathrm{Dy}^{3+}$ powders heated at $800-1200{ }^{\circ} \mathrm{C}$ are represented in Fig. 1. All diffraction peaks of these specimens present a good match with the standard phase of $\mathrm{NaSrPO}_{4}(\mathrm{PDF} \# 33-1282)$ [32] and can be indexed as a monoclinic crystal with lattice parameters of $a=20.414 \AA, b=5.429 \AA$, and $c=17.426 \AA$. This proves that $\mathrm{NaSrPO}_{4}: \mathrm{Dy}^{3+}$ samples with $\mathrm{NaSrPO}_{4}$ structure are successfully prepared and no obvious impurity phases corresponding to $\mathrm{Dy}^{3+}$ appear. In addition, a low $\mathrm{Dy}^{3+}$-ion doping concentration does not lead to significant phase changes in the $\mathrm{NaSrPO}_{4}$ structure in view of the close ionic radii of $\mathrm{Sr}^{2+}(r=0.118 \mathrm{~nm})$ and $\mathrm{Dy}^{3+}(\mathrm{r}=$ $0.091 \mathrm{~nm}$ ). Table 1 displays the corresponding lattice parameters and volumes of these samples. Apparently, increasing the thermal energy enhances diffusion and migration among diverse ions, which causes a slight decrease in cell volume. This can be interpreted as resulting from an increasing number of $\mathrm{Dy}^{3+}$ ions entering the host structure to form a luminescence center [36].

The SEM images and corresponding EDS results of $\mathrm{NaSrPO}_{4}: \mathrm{Dy}^{3+}$ samples prepared at $800{ }^{\circ} \mathrm{C}$ and $1000{ }^{\circ} \mathrm{C}$ are shown in Fig. 2. The samples prepared at $800{ }^{\circ} \mathrm{C}$ and $1000{ }^{\circ} \mathrm{C}$ (Figs. 2(a) and 2(b), respectively) exhibit homogeneous size distributions with particle diameters of about $2 \mu \mathrm{m}$ and $4 \mu \mathrm{m}$ at $800^{\circ} \mathrm{C}$ and $1000{ }^{\circ} \mathrm{C}$, respectively. Meanwhile, the particle sizes increase rapidly with increases in synthesis temperature. As the synthesis temperature increases, the particle size and degree of bonding are affected to some extent. For these grains acquire an increasing thermal energy, there is a tighter bonding among particles, and the particle size of the phosphor prepared at $1000{ }^{\circ} \mathrm{C}$ is larger than that prepared at $800^{\circ} \mathrm{C}$. Moreover, the EDS spectrum shown in Fig. 2(c) provides a distribution of the elemental content at a marker point. The elemental weight percentage of the $\mathrm{NaSrPO}_{4}: 2 \% \mathrm{Dy}^{3+}$ sample prepared at $1000{ }^{\circ} \mathrm{C}$ and 
stoichiometric atom ratio are listed and compared. It can be clearly observed that the sample contained the elements $\mathrm{O}, \mathrm{Na}, \mathrm{P}, \mathrm{Sr}$, and Dy. Compared with the elemental weight percentage of the stoichiometric ratio obtained by theoretical calculation, the as-prepared phosphor has good correspondence to the standard composition, and only a small amount of $\mathrm{Na}$ is evaporated at high temperature.

Fig. 3 illustrates the emission spectra of $\mathrm{NaSrPO}_{4}: \mathrm{Dy}^{3+}$ processed at specified temperatures with an excitation at $348 \mathrm{~nm}$. Two emission peaks located at $484 \mathrm{~nm}$ (blue) and $577 \mathrm{~nm}$ (yellow), which originated from the magnetic dipole transition ${ }^{4} \mathrm{~F}_{9 / 2} \rightarrow{ }^{6} \mathrm{H}_{15 / 2}$ and electronic dipole transition ${ }^{4} \mathrm{~F}_{9 / 2} \rightarrow{ }^{6} \mathrm{H}_{13 / 2}$ of $\mathrm{Dy}^{3+}$ ions, respectively. There are no significant shifts of the emission peaks, although the luminescence intensities of $\mathrm{NaSrPO}_{4}: \mathrm{Dy}^{3+}$ increases with synthesis temperature up to $1000{ }^{\circ} \mathrm{C}$ and later declines. The synthesis temperature produces two concrete roles on its interior structure, which affects the luminescence property of the specimens [14]: On one hand, the crystallization of $\mathrm{NaSrPO}_{4}$ and diffusion of the $\mathrm{Dy}^{3+}$ ions in the structure are favored by high temperatures; on the other hand, heating at high temperatures leads to the formation of large crystal grains. At synthesis temperatures of $800-1000{ }^{\circ} \mathrm{C}$, the first aspect acts a critical section in improving the luminescence performance, while the second affects the luminescence obtained above $1000{ }^{\circ} \mathrm{C}$.

$\mathrm{As} \mathrm{Dy}^{3+}$ ions are the luminescence center, the $\mathrm{Dy}^{3+}$ doping concentration significantly influences the relevant luminescence intensities of these as-prepared powders. The XRD mappings of $\mathrm{NaSrPO}_{4}: x \mathrm{Dy}^{3+}$ samples with particular $\mathrm{Dy}^{3+}$ amounts are represented in Fig. 4. With increased $\mathrm{Dy}^{3+}$ doping concentrations, the diffraction mappings of all as-prepared powders exhibit much consistency in the standard $\mathrm{NaSrPO}_{4}$ structure without impurity peaks, indicating that $\mathrm{Dy}^{3+}$ ions do not affect the host structure. 
By zooming the patterns in the $2 \theta$ angle range of $30^{\circ}-34^{\circ}$, an enlarged image of the main diffraction peaks is obtained (Fig. 4(b)). As smaller Dy ${ }^{3+}(0.091 \mathrm{~nm})$ ions successfully enter the larger $\mathrm{Sr}^{2+}(\mathrm{r}=0.118 \mathrm{~nm})$ sites in the monoclinic crystal lattice of $\mathrm{NaSrPO}_{4}$, the diffraction peaks offset mildly to the larger $2 \theta$ angle positions. Moreover, the unit-cell volume of $\mathrm{Dy}^{3+}$-doped $\mathrm{NaSrPO}_{4}$ is slightly lower than that of the original host, as shown in Table 2.

The excitation spectrum $\left(\lambda_{\mathrm{em}}=484 \mathrm{~nm}\right), \mathrm{UV}$-Visible absorption spectrogram, and emission spectra $\left(\lambda_{\mathrm{ex}}=348 \mathrm{~nm}\right)$ of as-prepared $\mathrm{NaSrPO}_{4}: x \mathrm{Dy}^{3+}$ are shown in Fig. 5. In Fig. 5(a), several apparent excitation peaks of $\mathrm{NaSrPO}_{4}: \mathrm{Dy}^{3+}$ are visible at $348 \mathrm{~nm}$, $384 \mathrm{~nm}, 362 \mathrm{~nm}, 322 \mathrm{~nm}$, and $424 \mathrm{~nm}$, which correspond to the ${ }^{6} \mathrm{H}_{15 / 2} \rightarrow{ }^{4} \mathrm{M}_{15 / 2}$, ${ }^{6} \mathrm{H}_{15 / 2} \rightarrow{ }^{4} \mathrm{M}_{21 / 2},{ }^{6} \mathrm{H}_{15 / 2} \rightarrow{ }^{4} \mathrm{P}_{3 / 2},{ }^{6} \mathrm{H}_{15 / 2} \rightarrow{ }^{4} \mathrm{~K}_{15 / 2}$ and ${ }^{6} \mathrm{H}_{15 / 2} \rightarrow{ }^{4} \mathrm{I}_{15 / 2}$ transitions of Dy ${ }^{3+}$ ions, respectively [35]. The excitation spectrum indicates that as-prepared $\mathrm{NaSrPO}_{4}: \mathrm{Dy}^{3+}$ phosphor is capable to be productively excited by ultraviolet radiation.

The UV-Vis absorption spectrogram of $\mathrm{NaSrPO}_{4}: \mathrm{Dy}^{3+}$ is shown in Fig. 5(b) for verification. The sample has an intense absorption region between $200 \mathrm{~nm}$ and 300 $\mathrm{nm}$, which match with the transient state of charge transfer between phosphorus and oxygen. Meanwhile, two visible absorption peaks at $348 \mathrm{~nm}$ and $384 \mathrm{~nm}$ that are highly consistent with the excitation spectrum and are also attributed to the ${ }^{6} \mathrm{H}_{15 / 2} \rightarrow{ }^{4} \mathrm{M}_{15 / 2}$ and ${ }^{6} \mathrm{H}_{15 / 2} \rightarrow{ }^{4} \mathrm{M}_{21 / 2}$ electronic transitions of $\mathrm{Dy}^{3+}$ ions. Moreover, the stronger absorption at $348 \mathrm{~nm}$ indicates that there is suitable excitation of $\mathrm{Dy}^{3+}$ ions, which can lead to the excellent photoluminescence property of $\mathrm{NaSrPO}_{4}: \mathrm{Dy}^{3+}$. The emission spectra of $\mathrm{NaSrPO}_{4}: \mathrm{Dy}^{3+}$ phosphors with $\mathrm{Dy}^{3+}$ concentrations $(\mathrm{x}=$ 0.5-4\%) are presented in Fig. 5(c). Under $348 \mathrm{~nm}$ excitation, two high-intensity emission peaks from $\mathrm{Dy}^{3+}$ are detected at $484 \mathrm{~nm}$ and $577 \mathrm{~nm}$. Therefore, the concentration of $\mathrm{Dy}^{3+}$ doping only affects the luminescence intensities but not the 
peak positions. The luminescence intensities of phosphors increase with increases in $\mathrm{Dy}^{3+}$ concentration from $0.5 \%$ to $2 \%$, resulting in increases in the luminescence centers, which reach a maximum at a doping concentration of $2 \%$. As the concentration increases further, a sudden fall in luminescence intensity appears because of the concentration quenching phenomenon.

White light can be generated by assembling the characteristic emission peaks of blue and yellow of $\mathrm{Dy}^{3+}$, so their luminescence intensities are important. Fig. 5(d) exhibits the relevance of the luminescence intensities of the two corresponding peaks on the specified $\mathrm{Dy}^{3+}$ concentration, which can explain the correlation between dosage concentration and the luminescence intensity ratios of the two corresponding peaks located in $484 \mathrm{~nm}$ and $577 \mathrm{~nm}\left(I_{484 \mathrm{~nm}} / I_{577} \mathrm{~nm}\right)$. The $I_{484 \mathrm{~nm}} / I_{577} \mathrm{~nm}$ ratios of $\mathrm{NaSrPO}_{4}: x \mathrm{Dy}^{3+}(x=0.5 \%, 1 \%, 2 \%, 3 \%$, and $4 \%)$ are calculated as $1.139,1.050$, $1.078,1.027$, and 1.044 , respectively. The calculation results reveal that the $I_{484} \mathrm{~nm} / I_{577}$ $\mathrm{nm}$ ratio can be altered by the $\mathrm{Dy}^{3+}$ doping concentration, although they are close to 1 . Hence, we suppose that better quality white light can be obtained through adjusting the ratio of $I_{484} \mathrm{~nm} / I_{577} \mathrm{~nm}$.

The Commission Internationale de l'Eclairage (CIE) chromaticity coordinates of $\mathrm{NaSrPO}_{4}: x \mathrm{Dy}^{3+}(x=0.5 \%, 1 \%, 2 \%, 3 \%$, and 4\%) phosphors are shown in Fig. 6 . It indicates the relevant coordinates of the samples sit in white-light area and are near to the standard white coordinates $(0.33,0.33)$. The coordinates of all phosphors are distributed on a line between the blue and yellow light points. Due to the influence of the blue-yellow ratio, the positions of the color coordinates also vary slightly. Therefore, it is suggested that ideal white-light will hopefully be manufactured via regulating the blue-yellow ratio and color coordinates. 
To further explore the concentration quenching phenomenon of luminescence among adjacent $\mathrm{Dy}^{3+}$ ions, the critical radius distance $\left(R_{c}\right)$ can be counted as [37]:

$$
R c=2\left(\frac{3 V}{4 \pi x_{c} N}\right)^{1 / 3}
$$

where $R_{c}$ denotes the critical distance, $V$ is the unit cell volume, $N$ represents the cation sites from a unit cell in $\mathrm{NaSrPO}_{4}$ host, and $x_{\mathrm{c}}$ refers the critical concentration of $\mathrm{Dy}^{3+}$. In this case, $R_{c}$ is calculated to be $22.50 \AA$ via applying the following reference values: $V=1907.85 \AA^{3}, x_{\mathrm{c}}=0.02, N=16$. A larger distance among $\mathrm{Dy}^{3+}$ ions makes the exchange interactions less effective, while a multipole interaction is superior. Accordingly, There are two types of energy transfer: one is exchange interaction, another is multipole-multipole interaction. Based on the calculation of $R_{c}(>5 \AA)$, the conclusion of multipole-multipole interaction mechanism plays main role in energy transfer of $\mathrm{Dy}^{3+}$ ions can be offered. To further analyze the mechanism, the following equation can be used according to Dexter's theory [38]:

$$
I / x=k /\left[1+\beta(x)^{Q / 3}\right]
$$

where $k$ and $\beta$ indicate two constants in a $\mathrm{NaSrPO}_{4}$ host; and $I$ and $x$ represent the luminescence intensity of $\mathrm{NaSrPO}_{4}: x \mathrm{Dy}^{3+}(x=2 \%, 3 \%, 4 \%, 5 \%, 6 \%)$ and molar fraction of the specific $\mathrm{Dy}^{3+}$ concentration, respectively. $Q$ shows the form of interaction among dipole-dipole, dipole-quadrupole, and quadrupole-quadrupole interactions, correspond to $Q=6,8$, and 10 , respectively. Provided $\beta(x)^{Q / 3}$ is much larger than 1, the above equation can be equivalently converted to the following [39]:

$$
\log (I / x)=C-\frac{Q}{3} \log (x) ;(C=\log k-\log \beta)
$$

Fig. 7 demonstrates the relevance of $\log (I / x)$ and $\log (x)$ of the $\mathrm{Dy}^{3+}$-ion peaks at 484 $\mathrm{nm}$ and $577 \mathrm{~nm}$. By fitting, the slopes of the lines are -2.3259 and -2.1890 , respectively. The $Q$ values are calculated as 6.9778 and 6.5670 , which are near to 6 . Hence, the dominating cause of concentration quenching of $\mathrm{NaSrPO}_{4}: x \mathrm{Dy}^{3+}$ can be 
considered to involve dipole-dipole interactions.

The above consequences are verified that white light is promising to be achieved through uniting the two characteristic blue and yellow emissions of $\mathrm{NaSrPO}_{4}: \mathrm{Dy}^{3+}$ phosphors. Moreover, $\mathrm{Sm}^{3+}$ ions should be co-doped in the phosphors to improve luminescence, especially the $C C T$ value.

The XRD patterns of $\mathrm{NaSrPO}_{4}: 2 \% \mathrm{Dy}^{3+}, y \mathrm{Sm}^{3+}(y=1 \%, 2 \%, 3 \%)$ phosphors are shown in Fig. 8. Like Fig. 4, the patterns for $\mathrm{NaSrPO}_{4}: \mathrm{Dy}^{3+}, \mathrm{Sm}^{3+}$ specimens are in keeping with the standard structure of $\mathrm{NaSrPO}_{4}$; hence, $\mathrm{Dy}^{3+}, \mathrm{Sm}^{3+}$ co-doping does not cause apparent variations in the host structure. Meanwhile, the lattice parameters and volumes of $\mathrm{NaSrPO}_{4}: \mathrm{Dy}^{3+}, \mathrm{Sm}^{3+}$ are revealed in Table 3 which interpret that small amounts of $\mathrm{Dy}^{3+}$ and $\mathrm{Sm}^{3+}$ ion doping have no distinct effect in the overall structure of the samples by cause of the close ionic radius among $\operatorname{Sr}^{2+}(r=0.118 \mathrm{~nm})$, $\operatorname{Dy}^{3+}(r=0.091 \mathrm{~nm})$, and $\mathrm{Sm}^{3+}(r=0.096 \mathrm{~nm})$. Compared with the standard $\mathrm{NaSrPO}_{4}$ structure, by virtue of the tiny difference in ion radius, the relevant cell volumes and lattice parameters of the as-prepared specimens decrease and distort slightly. In addition, this phenomenon shows that $\mathrm{Dy}^{3+}$ and $\mathrm{Sm}^{3+}$ ions enter the host structure without altering its structure.

The emission spectra $\left(\lambda_{\mathrm{ex}}=348 \mathrm{~nm}\right)$ and corresponding energy transfer efficiency of $\mathrm{NaSrPO}_{4}: 2 \% \mathrm{Dy}^{3+}, y \mathrm{Sm}^{3+}$ phosphors with specified $\mathrm{Sm}^{3+}$ co-doping concentrations are put forward in Fig. 9. Apart from the two original peaks of $\mathrm{Dy}^{3+}$ ions located at 484 nm and $577 \mathrm{~nm}$, a new emission peak appears at $602 \mathrm{~nm}$ (Fig. 9(a)), which stems from the characteristic ${ }^{4} \mathrm{G}_{5 / 2} \rightarrow{ }^{6} \mathrm{H}_{7 / 2}$ transition from $\mathrm{Sm}^{3+}$. The results show that as the co-doping concentration of $\mathrm{Sm}^{3+}$ increases gradually, the luminescence intensities of the $\mathrm{Sm}^{3+}$ characteristic peak at $602 \mathrm{~nm}$ increase, while the luminescence intensities of the $\mathrm{Dy}^{3+}$ characteristic emission peaks decrease. This phenomenon is interpreted as 
the result of transmission in energy from $\mathrm{Dy}^{3+}$ to $\mathrm{Sm}^{3+}$.

The energy transfer efficiency $\left(\eta_{\mathrm{ET}}\right)$ between $\mathrm{Dy}^{3+}$ and $\mathrm{Sm}^{3+}$ can be calculated as follows:

$$
\eta_{\mathrm{ET}}=1-\frac{I_{S}}{I_{s 0}}
$$

where $I_{S 0}$ expresses the intrinsic luminescence intensity of single-doped $\mathrm{Dy}^{3+}$ and $I_{S}$ refers to the luminescence intensity of $\mathrm{NaSrPO}_{4}: 2 \% \mathrm{Dy}^{3+}$ co-doping $\mathrm{Sm}^{3+}$. Hence, the $\eta_{\text {ET }}$ values, accompanying $\mathrm{Sm}^{3+}$ concentrations of $1 \%, 2 \%$, and $3 \%$ are calculated as 34.7\%, 47.6\%, and 70.6\%, respectively (Fig. 9(b)).

To describe the energy transfer $\left(\mathrm{Dy}^{3+} \rightarrow \mathrm{Sm}^{3+}\right)$ and their level structure more clearly, a schematic plot of energy transfer is presented in Fig. 10. Under UV-light irradiation, the electrons in the $4 \mathrm{f}$ electronic shell of $\mathrm{Dy}^{3+}$ in the ground-state orbitals ${ }^{6} \mathrm{H}_{15 / 2}$ absorb light and leap into higher energy levels $\left({ }^{6} \mathrm{P}_{7 / 2},{ }^{6} \mathrm{P}_{5 / 2},{ }^{4} \mathrm{I}_{15 / 2}\right.$, etc.). Radiative transition occurs among high energy levels and results in the electrons falling into the ${ }^{4} \mathrm{~F}_{9 / 2}$ level. Subsequently, absorbed energy is released as the $\mathrm{Dy}^{3+}$ electrons get back to the ground-state orbitals of ${ }^{6} \mathrm{H}_{15 / 2}$ and ${ }^{6} \mathrm{H}_{13 / 2}$, realizing two characteristic blue light (484 nm) and yellow light emissions (577 nm). Meanwhile, some of the energy is transferred to $\mathrm{Sm}^{3+}$ electrons from $\mathrm{Dy}^{3+}$. Electrons of $\mathrm{Sm}^{3+}$ in ground state transition to an excited state ${ }^{6} \mathrm{P}_{3 / 2}$ after gaining transfer energy. Accompanied by radiative transition, the high-energy electrons of $\mathrm{Sm}^{3+}$ migrate to three ground states ${ }^{6} \mathrm{H}_{5 / 2}(566$ nm) ${ }^{6} \mathrm{H}_{7 / 2}(602 \mathrm{~nm})$ and ${ }^{6} \mathrm{H}_{9 / 2}(649 \mathrm{~nm})$ from the ${ }^{4} \mathrm{G}_{5 / 2}$ excited state and a characteristic red emission is produced.

To further verify the $\mathrm{Dy}^{3+} \rightarrow \mathrm{Sm}^{3+}$ energy transfer, decay curves are depicted to evaluate the luminescence lifetimes of $\mathrm{Dy}^{3+}\left({ }^{4} \mathrm{~F}_{9 / 2} \rightarrow{ }^{6} \mathrm{H}_{13 / 2}\right)$ and $\mathrm{Sm}^{3+}\left({ }^{4} \mathrm{G}_{5 / 2} \rightarrow{ }^{6} \mathrm{H}_{7 / 2}\right)$ in $\mathrm{NaSrPO}_{4}: 2 \% \mathrm{Dy}^{3+}, y \mathrm{Sm}^{3+}(y=1 \%, 2 \%, 3 \%)$ phosphors (Fig. 11). The decay curves which identify with an especial function of double exponential, can be fitted via the 
formula [40]:

$$
I(t)=I_{0}+A_{1} \exp \left(-t / \tau_{1}\right)+A_{2} \exp \left(-t / \tau_{2}\right)
$$

where $A_{1}$ and $A_{2}$ are fitting constants; while $\tau_{1}$ and $\tau_{2}$ signify the lifetimes of exponential sections; $I_{0}$ and $I(t)$ represent the luminescence intensities at times 0 and $t$, respectively. Conforming to the above parameters, the decay times for different concentrations of $\mathrm{Sm}^{3+}$ co-doped $\mathrm{NaSrPO}_{4}: 2 \% \mathrm{Dy}^{3+}$ phosphors can be assessed through the following functional equation [41]:

$$
\tau=\left(A_{1} \tau_{1}^{2}+A_{2} \tau_{2}^{2}\right) /\left(A_{1} \tau_{1}+A_{2} \tau_{2}\right)
$$

Compared with $\mathrm{Dy}^{3+}$-doped phosphors, $\mathrm{Dy}^{3+}$ - and $\mathrm{Sm}^{3+}$-codoped samples monitored at $484 \mathrm{~nm}$ show decay-time decreases from $1.2823 \mathrm{~ms}$ to $0.9564 \mathrm{~ms}$, along with the specified $\mathrm{Sm}^{3+}$ doping concentrations gradually increase from $1 \%$ to $3 \%$. Meanwhile, the decay times monitored at $602 \mathrm{~nm}$ increase from $2.1274 \mathrm{~ms}$ to $2.8006 \mathrm{~ms}$. Briefly, energy is capable of being transferred effectively from $\mathrm{Dy}^{3+}$ to $\mathrm{Sm}^{3+}$.

The CIE chromaticity coordinates of $\mathrm{NaSrPO}_{4}: \mathrm{Dy}^{3+}, \mathrm{Sm}^{3+}$ phosphors are measured and summarized in Table 4. Compared with the standard white-light point $(0.33$, 0.33), all the calculated values move from the white to the near red region. The $C C T$, a standard measure of color temperature used to reflect lighting quality, can be provided via the equation [42]:

$$
C C T=-437 n^{3}+3601 n^{2}-6861 n+5514.31
$$

where $n=\left(x-x_{e}\right) /\left(y-y_{e}\right)$; and $x_{e}$ and $y_{e}$ both equal 0.33 ; and $y_{e}$ equal 0.1858 . Although the $\mathrm{NaSrPO}_{4}: \mathrm{Dy}^{3+}$ phosphor with the $2 \%$ doping concentration has a higher luminescence intensity, its CCT value is as high as $5695 \mathrm{~K}$, which can be considered a "cold" white light (blueish). Fig.12 represents the CIE chromaticity coordinates of samples under different doping contents. Along with the specific dosage of $\mathrm{Sm}^{3+}$ are added into $\mathrm{NaSrPO}_{4}: 2 \% \mathrm{Dy}^{3+}$ phosphors, the $C C T$ values decrease from $4506 \mathrm{~K}$ to 
$3989 \mathrm{~K}$, accompanied by a variation in light color from neutral white to "warm" white (reddish). Hence, it illustrates that the CIE chromaticity coordinates are effectively alterable by regulating the doping ratios of $\mathrm{Dy}^{3+}$ and $\mathrm{Sm}^{3+}$. The external quantum efficiencies of $\mathrm{NaSrPO}_{4}: 2 \% \mathrm{Dy}^{3+}, \mathrm{ySm}^{3+}(\mathrm{y}=1 \%, 2 \%)$ phosphors are measured as $25.2 \%$ and $21.4 \%$, respectively. All results indicate that the $\mathrm{NaSrPO}_{4}: \mathrm{Dy}^{3+}, \mathrm{Sm}^{3+}$ phosphor has great potential for use in commercial applications requiring warm white light.

\section{Conclusion}

In summary, $\mathrm{NaSrPO}_{4}: \mathrm{Dy}^{3+}, \mathrm{Sm}^{3+}$ phosphors were synthesized through a sol-gel method and the white-light emissions from $\mathrm{Dy}^{3+}$ and $\mathrm{Sm}^{3+}$ were surveyed in detail. The PL spectra indicate that $\mathrm{NaSrPO}_{4}: \mathrm{Dy}^{3+}$ samples are effectively excited by UV light of $348 \mathrm{~nm}$, and emissions with characteristic peaks at $484 \mathrm{~nm}$ and $577 \mathrm{~nm}$ combine into white light. The quenching concentration of $\mathrm{NaSrPO}_{4}: \mathrm{Dy}^{3+}$ is $2 \%$, which coincides with the dipole-dipole interactions. By co-doping with $\mathrm{Sm}^{3+}$ ions, $\mathrm{NaSrPO}_{4}: \mathrm{Dy}^{3+}$ phosphors are supposed to be regulated to realize warm white light emission with a lower $C C T$ value. Meanwhile, energy transfer from $\mathrm{Dy}^{3+}$ to $\mathrm{Sm}^{3+}$ ions in the $\mathrm{NaSrPO}_{4}$ structure is proven. The results suggest that $\mathrm{NaSrPO}_{4}: \mathrm{Dy}^{3+}, \mathrm{Sm}^{3+}$ phosphors are strong candidates for application to w-LEDs.

\section{Declaration of competing interest}

The authors declare that they have no known competing financial interests or personal relationships that could have appeared to influence the work reported in this paper.

\section{References}

[1] J. Lai, Z. Long, J. Qiu, D. Zhou, J. Zhou, C. Zhu, S. Hu, K. Zhang, Q. Wang, Warm white light emitting from single composition $\mathrm{SrGa}_{12} \mathrm{O}_{19}: \mathrm{Dy}^{3+}$ phosphors for ACLED. J. Am. Ceram. Soc. 103, 335-345 (2019). 
[2] H. Qian, J. Zhang, L. Yin, Crystal structure and optical properties of white lightemitting $\mathrm{Y}_{2} \mathrm{WO}_{6}: \mathrm{Sm}^{3+}$ phosphor with excellent color rendering, RSC Advances 3, 9029-9034 (2013).

[3] R.-S. Liu, Y.-H. Liu, N.C. Bagkar, S.-F. Hu, Enhanced luminescence of $\mathrm{SrSi}_{2} \mathrm{O}_{2} \mathrm{~N}_{2}: \mathrm{Eu}^{2+}$ phosphors by codoping with $\mathrm{Ce}^{3+}, \mathrm{Mn}^{2+}$, and $\mathrm{Dy}^{3+}$ ions, Appl. Phys. Lett. 91, 061119 (2007).

[4] Z. Li, Y. Wang, J. Cao, Y. Jiang, X. Zhao, Z. Meng, Hydrothermal synthesis and luminescent properties of $\mathrm{BaMoO}_{4}: \mathrm{Sm}^{3+}$ red phosphor. J. Rare Earths 34, $143-$ 7 (2016).

[5] C. Wei, D. Xu, Z. Yang, J. Li, X. Chen, X. Li, J. Sun, Insight into the synthesis and luminescence properties of the single-ion-activated single-phased $\mathrm{Na}_{3} \mathrm{ScSi}_{2} \mathrm{O}_{7}: \mathrm{Dy}^{3+}$ phosphor for white light-emitting diodes, Appl. Phys. A 125, 1-6 (2019).

[6] S. Sharma, S. Pitale, M. Malik, M. Qureshi, R. Dubey, Spectral and kinetic characterization of orange-red emitting $\mathrm{Sr}_{3} \mathrm{Al}_{2} \mathrm{O}_{6}: \mathrm{Eu}^{3+} / \mathrm{Sm}^{3+}$ phosphor, J. Alloys Compd. 482, 468-475 (2009).

[7] F. Xie, J. Li, Z. Dong, D. Wen, J. Shi, J. Yan, M. Wu, Energy transfer and luminescent properties of $\mathrm{Ca} 8 \mathrm{MgLu}\left(\mathrm{PO}_{4}\right)_{7}: \mathrm{Tb}^{3+} / \mathrm{Eu}^{3+}$ as a green-to-red color tunable phosphor under NUV excitation, RSC Advances 5, 59830-59836 (2015).

[8] M. Chen, K. Qiu, P. Zhang, W. Zhang, Q. Yin, Enhancement of $\mathrm{NaSrVO}_{4}: \mathrm{Dy}^{3+}{ }_{-}$ white-phosphor photoluminescence via $\mathrm{La}^{3+}$ co-doping, Ceram. Int. 45, 22547-22552 (2019).

[9] J. Zhang, Q. Guo, L. Liao, Y. Wang, M. He, H. Ye, L. Mei, H. Liu, T. Zhou, B. $\mathrm{Ma}$, Structure and luminescence properties of $\mathrm{La}_{6} \mathrm{Ba}_{4}\left(\mathrm{SiO}_{4}\right)_{6} \mathrm{~F}_{2}: \mathrm{Dy}^{3+}$ phosphor with apatite structure, RSC Advances 8, 38883-38890 (2018).

[10] J.-j. Zhang, J.-w. Ning, X.-j. Liu, Y.-b. Pan, L.-p. Huang, Synthesis of ultrafine 
YAG:Tb phosphor by nitrate-citrate sol-gel combustion process, Mater. Res. Bull. 38, 1249-1256 (2003).

[11] R. Kasuya, T. Isobe, H. Kuma, J. Katano, Photoluminescence enhancement of PEG-modified YAG:Ce ${ }^{3+}$ nanocrystal phosphor prepared by glycothermal method, J. Phys. Chem. B 109, 22126-22130 (2005).

[12] V. Singh, S. Watanabe, T. Rao, J. Chubaci, H. Kwak, Luminescence and defect centers in $\mathrm{MgSrAl}_{10} \mathrm{O}_{17}: \mathrm{Sm}^{3+}$ phosphor, J. Non-Cryst. Solids 356, 1185-1190 (2010).

[13] V. Kumar, A. Bedyal, S. Pitale, O. Ntwaeaborwa, H. Swart, Synthesis, spectral and surface investigation of $\mathrm{NaSrBO}_{3}: \mathrm{Sm}^{3+}$ phosphor for full color down conversion in LEDs, J. Alloys Compd. 554, 214-220 (2013).

[14] W. Zhang, G. Yan, S. Dai, P. Zhang, Q. Zhao, K. Qiu, M. Deng, Effects of charge compensator $\mathrm{Li}^{+}$co-doping on the structure and luminescence properties of $\mathrm{Cd}_{2} \mathrm{~V}_{2} \mathrm{O}_{7}: \mathrm{Eu}^{3+}$ red phosphors, Ceram. Int. 44, 9534-9539 (2018).

[15] Qinyu Li, Lan Yu, Weiping Wu, Chang Liu, Mengjiao Liu, Ling Huang, Yan Zhao, Xin Lai, Jian Bi, Daojiang Gao, Novel BaGe1-x $\mathrm{Si}_{\mathrm{x}} \mathrm{F}_{6}: \mathrm{Mn}^{4+}(0 \leq \mathrm{x} \leq 1)$ red phosphors for warm white LEDs: Hydrothermal synthesis and photoluminescence properties, J. Alloys Compd. 852, 156995 (2021).

[16] S. You, Y. Zhuo, Q. Chen, J. Brgoch, R.-J. Xie, Dual-site occupancy induced broadband cyan emission in $\mathrm{Ba}_{2} \mathrm{CaB}_{2} \mathrm{Si}_{4} \mathrm{O}_{14}: \mathrm{Ce}^{3+}$, J. Mater. Chem. C 8, 15626-15633 (2020).

[17] Z. Jia, X. Zhang, X. Hua, Y. Dong, H. Li, C. Feng, Y. Wang, M. Xia, Engineering mixed polyanion red-emitting $\mathrm{Rb}_{2} \mathrm{Bi}\left(\mathrm{PO}_{4}\right)\left(\mathrm{WO}_{4}\right)$ : $\mathrm{Eu}^{3+}$ phosphors with negligible thermal quenching and high quantum yield, J. Alloys Compd. 844, 155875 (2020). [18] H. Luitel, T. Watari, R. Chand, T. Torikai, M. Yada, Photoluminescence properties of a novel orange red emitting $\mathrm{Sr}_{4} \mathrm{Al}_{14} \mathrm{O}_{25}: \mathrm{Sm}^{3+}$ phosphor and PL 
enhancement by $\mathrm{Bi}^{3+}$ co-doping, Opt. Mater. 34, 1375-1380 (2012).

[19] J. Hou, X. Yin, F. Huang, W. Jiang, Synthesis and photoluminescence properties of $\mathrm{NaLaMgWO}_{6}: \mathrm{RE}^{3+}(\mathrm{RE}=\mathrm{Eu}, \mathrm{Sm}, \mathrm{Tb})$ phosphor for white LED application, Mater. Res. Bull. 47, 1295-1300 (2012).

[20] R. Mahajan, R. Prakash, Synthesis and effect of $\mathrm{Dy}^{3+}$ doping on vibrational and luminescent properties of $\mathrm{Mg}_{2} \mathrm{Zn}\left(\mathrm{PO}_{4}\right)_{2}$, J. Mater. Sci.-Mater. Electron. 31, 3861$3868(2020)$

[21] Q. Xu, J. Sun, D. Cui, Q. Di, J. Zeng, Synthesis and luminescence properties of novel $\mathrm{Sr}_{3} \mathrm{Gd}\left(\mathrm{PO}_{4}\right)_{3}: \mathrm{Dy}^{3+}$ phosphor, J. Lumin. 158, 301-305 (2015).

[22] J. Kuang, Y. Liu, J. Zhang, White-light-emitting long-lasting phosphorescence in $\mathrm{Dy}^{3+}$ doped $\mathrm{SrSiO}_{3}$, J. Solid State Chem. 179, 266-269 (2006).

[23] X. Yu, Z. Han, H. Tang, J. Xie, X. Mi, Investigating luminescence properties and energy transfer of $\mathrm{Ca}_{3}\left(\mathrm{PO}_{4}\right)_{2}: \mathrm{Dy}^{3+} / \mathrm{Eu}^{3+}$ phosphor via hydrothermal synthesis, Opt. Mater. 106, 110009 (2020).

[24] M. Fhoula, T. Koubaa, M. Dammak, White photoluminescence and energy transfer properties of Dysprosium and Europium singly and codoped $\mathrm{Na}_{2} \mathrm{ZnP}_{2} \mathrm{O}_{7}$ phosphors, Opt. Laser Technol. 130, 106352 (2020).

[25] G. Zhu, Z.-W. Li, C. Wang, F.-G. Zhou, Y. Wen, S.-Y. Xin, Electronic structure and photoluminescence property of a novel white emission phosphor $\mathrm{Na} 3 \mathrm{MgZr}\left(\mathrm{PO}_{4}\right)_{3}: \mathrm{Dy}^{3+}$ for warm white light emitting diodes, Chinese Phys. B 26, 097801 (2017).

[26] Q. Liu, Y. Liu, Y. Ding, Z. Peng, X. Tian, Q. Yu, G. Dong, A white light emitting luminescent material $\mathrm{Ba}_{3} \mathrm{Y}\left(\mathrm{PO}_{4}\right)_{3}: \mathrm{Dy}^{3+}$, Ceram. Int. 40, 10125-10129 (2014). [27] B. Han, H. Liang, H. Lin, W. Chen, Q. Su, G. Yang, G. Zhang, Enhanced luminescence of $\mathrm{Ba} \mathrm{La}_{3}\left(\mathrm{PO}_{4}\right)_{3}: \mathrm{Dy}^{3+}$ by codoping $\mathrm{Gd}^{3+}$ ions and energy transfer 
between $\mathrm{Gd}^{3+}$ and $\mathrm{Dy}^{3+}$, J. Opt. Soc. Am. B 25, 2057-2063 (2008).

[28] X. Xu, Y. Wang, Y. Gong, W. Zeng, Y. Li, Effect of oxygen vacancies on the red phosphorescence of $\mathrm{Sr}_{2} \mathrm{SnO}_{4}: \mathrm{Sm}^{3+}$ phosphor. Opt. Express 18, 16989-16994 (2010). [29] M. Yu, W. Zhang, G. Yan, S. Dai, Z. Qiu, L. Zhang, Warm white emission property of $\mathrm{Ca}_{2} \mathrm{Sr}\left(\mathrm{PO}_{4}\right)_{2}: \mathrm{Dy}^{3+}$ phosphors with red compensation by $\mathrm{Eu}^{3+}$ co-doping, Ceram. Int. 44, 2563-2567 (2018).

[30] C. B. Palan, S. K.Omanwar, Effect of synthesis methods on luminescence properties of $\mathrm{LiCaPO}_{4}$ :Ce phosphor for radiation dosimetry, J. Lumin. 178, 340-346 (2016).

[31] S.A. Khan, A. Jalil, Q.U. Khan, R.M. Irfan, I. Mehmood, K. Khan, M. Kiani, B. Dong, N.Z. Khan, J.-L. Yu, L. Zhu, S. Agathopoulos, New physical insight into crystal structure, luminescence and optical properties of $\mathrm{YPO}_{4}: \mathrm{Dy}^{3+} \backslash \mathrm{Eu}^{3+} \backslash \mathrm{Tb}^{3+}$ singlephase white-light-emitting phosphors, J. Alloys Compd. 817, 152687 (2020). [32] J. Sun, J. Zhu, X. Zhang, Z. Xia, H. Du, Luminescent properties and energy transfer of double-emitting $\mathrm{NaSrPO}_{4}: \mathrm{Eu}^{2+}, \mathrm{Tb}^{3+}$ phosphor for near-UV white LEDs, J. Lumin. 132, 2937-2942 (2012).

[33] S. Huang, Y. Chen, X. Wei, M. Yin, Synthesis and Luminescence Properties of $\mathrm{NaSrPO}_{4}: \mathrm{Eu}^{2+}, \mathrm{Tb}^{3+}, \mathrm{Mn}^{2+}$ for WLED, J. Nanosci. Nanotechno. 14, 4574-4578 (2014).

[34] Y. Li, J. Chen, C. Chen, Tunable correlated color temperature of $\mathrm{NaSrPO}_{4}$ phosphors via $\mathrm{Dy}^{3+}$ and $\mathrm{Eu}^{3+}$ co-doping for warm white light-emitting diodes, Optik 174, 1-6 (2018).

[35] Z. Hu, T. Meng, W. Zhang, D. Ye, Y. Cui, L. Luo, Y. Wang, Synthesis and luminescence of $\mathrm{Dy}^{3+}$-activated $\mathrm{NaSrPO}_{4}$ phosphors for novel white light generation, J. Mater. Sci.-Mater. Electron. 25, 1933-1937 (2014). 
[36] L. Cheng, W. Zhang, Y. Li, S. Dai, K. Qiu, Synthesis and photoluminescence properties of $\mathrm{Sr}_{3}\left(\mathrm{PO}_{4}\right)_{2}: \mathrm{Re}^{3+}, \mathrm{Li}^{+}(\mathrm{Re}=\mathrm{Eu}, \mathrm{Sm})$ red phosphors for white light-emitting diodes, Ceram. Int. 43, 11244-11249 (2017).

[37] G. Blasse, Energy transfer in oxidic phosphors, Phys. Lett. A 28, 444-445 (1968).

[38] B. Devakumar, P. Halappa, C. Shivakumara, $\mathrm{Dy}^{3+} / \mathrm{Eu}^{3+}$ co-doped CsGd( $\left(\mathrm{MoO}_{4}\right)_{2}$ phosphor with tunable photoluminescence properties for near-UV WLEDs applications, Dyes Pigments 137, 244-255 (2016).

[39] K.H. Lee, S.H. Park, H.S. Yoon, Y.I. Kim, H.G. Jang, W.B. Im, Bredigitestructure orthosilicate phosphor as a green component for white LED: the structural and optical properties, Opt. Express 20, 6248-6257 (2012).

[40] Z. Xia, D. Chen, Synthesis and Luminescence Properties of $\mathrm{BaMoO}_{4}: \mathrm{Sm}^{3+}$ Phosphors, J. Am. Ceram. Soc. 93, 1397-1401 (2010).

[41] R. Jung, H. Jeong, Y.-F. Wang, A novel $\mathrm{Eu}^{3+}$ - and self-activated vanadate phosphor of $\mathrm{Ca}_{4} \mathrm{La}\left(\mathrm{VO}_{4}\right)_{3} \mathrm{O}$ with oxyvanadate apatite structure, J. Am. Ceram. Soc. 100, 5649-5658 (2017).

[42] J. An, Z. Zhang, Y. Qiu, Z. Fu, Y. Zhou, F. Zeng, Luminescence properties of borosilicate glass doped with $\mathrm{Ce}^{3+} / \mathrm{Dy}^{3+} / \mathrm{Eu}^{3+}$ under ultraviolet excitation for white LED, J. Non-Cryst. Solids 503-504, 208-213 (2019). 


\section{Tables}

Table 1 Lattice parameters and volumes of standard $\mathrm{NaSrPO}_{4}$ and $\mathrm{NaSrPO}_{4}: 2 \% \mathrm{Dy}^{3+}$ samples prepared at different temperatures.

\begin{tabular}{ccccc}
\hline Sample & $a(\AA)$ & $b(\AA)$ & $c(\AA)$ & $V\left(\AA^{3}\right)$ \\
\hline Standard & 20.414 & 5.429 & 17.246 & 1911.33 \\
$900{ }^{\circ} \mathrm{C}$ & 20.409 & 5.425 & 17.240 & 1909.12 \\
$1000^{\circ} \mathrm{C}$ & 20.408 & 5.421 & 17.245 & 1907.85 \\
$1100{ }^{\circ} \mathrm{C}$ & 20.411 & 5.419 & 17.237 & 1906.54 \\
\hline
\end{tabular}

Table 2 Lattice parameters and volumes of $\mathrm{NaSrPO}_{4}$ doped with $\mathrm{Dy}^{3+}$ doping concentrations.

\begin{tabular}{ccccc}
\hline Sample & $a(\AA)$ & $b(\AA)$ & $c(\AA)$ & $V\left(\AA^{3}\right)$ \\
\hline $\mathrm{NaSrPO}_{4}: 1 \% \mathrm{Dy}^{3+}$ & 20.411 & 5.428 & 17.236 & 1909.59 \\
$\mathrm{NaSrPO}_{4}: 2 \% \mathrm{Dy}^{3+}$ & 20.405 & 5.423 & 17.241 & 1907.83 \\
$\mathrm{NaSrPO}_{4}: 3 \% \mathrm{Dy}^{3+}$ & 20.406 & 5.422 & 17.216 & 1904.80 \\
$\mathrm{NaSrPO}_{4}: 4 \% \mathrm{Dy}^{3+}$ & 20.403 & 5.418 & 17.187 & 1899.91 \\
\hline
\end{tabular}

Table 3 Lattice parameters and volumes of $\mathrm{NaSrPO}_{4}$ co-doped with $\mathrm{Dy}^{3+}$ and $\mathrm{Sm}^{3+}$ co-doping concentrations.

\begin{tabular}{ccccc}
\hline Sample & $\mathrm{a}(\AA)$ & $\mathrm{b}(\AA)$ & $\mathrm{c}(\AA)$ & $\mathrm{V}\left(\AA^{3}\right)$ \\
\hline $2 \% \mathrm{Dy}^{3+}, 1 \% \mathrm{Sm}^{3+}$ & 20.359 & 5.426 & 17.246 & 1905.13 \\
$2 \% \mathrm{Dy}^{3+}, 2 \% \mathrm{Sm}^{3+}$ & 20.378 & 5.424 & 17.212 & 1902.45 \\
$2 \% \mathrm{Dy}^{3+}, 3 \% \mathrm{Sm}^{3+}$ & 20.399 & 5.414 & 17.218 & 1901.56 \\
\hline
\end{tabular}


Table 4 CIE parameters of the $\mathrm{NaSrPO}_{4}: 2 \% \mathrm{Dy}^{3+}$ and $\mathrm{NaSrPO}_{4}: 2 \% \mathrm{Dy}^{3+}, y \mathrm{Sm}^{3+}$ phosphors.

\begin{tabular}{ccccc}
\hline Point & Sample & $\mathrm{CIE}(\mathrm{x}, \mathrm{y})$ & $C C T / \mathrm{K}$ & Light color \\
\hline a & $\mathrm{NaSrPO}_{4}: 2 \% \mathrm{Dy}^{3+}$ & $(0.3408,0.3722)$ & 5129 & Cold white light \\
b & $\mathrm{NaSrPO}_{4}: 2 \% \mathrm{Dy}^{3+}, 1 \% \mathrm{Sm}^{3+}$ & $(0.3592,0.3697)$ & 4506 & Neutral white light \\
c & $\mathrm{NaSrPO}_{4}: 2 \% \mathrm{Dy}^{3+}, 2 \% \mathrm{Sm}^{3+}$ & $(0.3821,0.4084)$ & 4100 & Neutral white light \\
d & $\mathrm{NaSrPO}_{4}: 2 \% \mathrm{Dy}^{3+}, 3 \% \mathrm{Sm}^{3+}$ & $(0.3893,0.4197)$ & 3989 & Warm white light \\
\hline
\end{tabular}




\section{Figure captions}

Figure 1 XRD patterns of $\mathrm{NaSrPO}_{4}: 2 \% \mathrm{Dy}^{3+}$ samples prepared at various synthesis temperatures.

Figure 2 SEM images of $2 \% \mathrm{Dy}^{3+}$-doped $\mathrm{NaSrPO}_{4}$ phosphor prepared at (a) $800{ }^{\circ} \mathrm{C}$ and (b) $1000{ }^{\circ} \mathrm{C}$ and (c) corresponding EDS results.

Figure 3 Emission spectra of $\mathrm{NaSrPO}_{4}: \mathrm{Dy}^{3+}$ phosphors under excitation of $348 \mathrm{~nm}$ synthesized at specific temperatures.

Figure 4 (a) XRD patterns of $\mathrm{NaSrPO}_{4}: \mathrm{xDy}^{3+}(x=1 \%, 2 \%, 3 \%, 4 \%)$ with specified $\mathrm{Dy}^{3+}$ ion concentrations and (b) enlarged patterns in the $2 \theta$ ranged $30^{\circ}-34^{\circ}$.

Figure 5 (a) Excitation spectrum $\left(\lambda_{\mathrm{em}}=484 \mathrm{~nm}\right)$ and (b) $\mathrm{UV}$-vis spectrum of $\mathrm{NaSrPO}_{4}: 2 \% \mathrm{Dy}^{3+}$ at $1000{ }^{\circ} \mathrm{C}$; (c) Emission spectra of $\mathrm{NaSrPO}_{4}: x \mathrm{Dy}^{3+}$ with different $\mathrm{Dy}^{3+}$ concentrations; (d) Relevance of the luminescence intensities of two corresponding peaks (blue and yellow) on $\mathrm{Dy}^{3+}$ doping concentration.

Figure 6 CIE coordinates of $\mathrm{NaSrPO}_{4}: \mathrm{Dy}^{3+}$ with specified $\mathrm{Dy}^{3+}$ ion concentrations. Figure 7 (a) Fitting results of $\log (I / x)$ and $\log (x)$ for the ${ }^{4} \mathrm{~F}_{9 / 2} \rightarrow{ }^{6} \mathrm{H}_{15 / 2}(484 \mathrm{~nm})$ and (b) ${ }^{4} \mathrm{~F}_{9 / 2} \rightarrow{ }^{6} \mathrm{H}_{13 / 2}(577 \mathrm{~nm})$ transitions of $\mathrm{Dy}^{3+}$ ions in $\mathrm{NaSrPO}_{4}: \mathrm{Dy}^{3+}$ phosphors.

Figure 8 XRD patterns of $\mathrm{NaSrPO}_{4}: 2 \% \mathrm{Dy}^{3+}, y \mathrm{Sm}^{3+}(y=1 \%, 2 \%, 3 \%)$ with specified $\mathrm{Sm}^{3+}$ ion concentrations.

Figure 9 (a) Emission spectra of $\mathrm{NaSrPO}_{4}: 2 \% \mathrm{Dy}^{3+}, y \mathrm{Sm}^{3+}$ with specified $\mathrm{Sm}^{3+}$ ion concentrations and (b) corresponding energy transfer efficiency from $\mathrm{Dy}^{3+}$ to $\mathrm{Sm}^{3+}$ in $\mathrm{NaSrPO}_{4}$ structure.

Figure 10 Schematic diagram of energy transfer from $\mathrm{Dy}^{3+}$ to $\mathrm{Sm}^{3+}$ in $\mathrm{NaSrPO}_{4}: \mathrm{Dy}^{3+}$, $\mathrm{Sm}^{3+}$ phosphor.

Figure 11 Decay curves of $\mathrm{NaSrPO}_{4}: 2 \% \mathrm{Dy}^{3+}, y \mathrm{Sm}^{3+}(y=1 \%, 2 \%$, and $3 \%)$ 
phosphors inspected at (a) $484 \mathrm{~nm}$ and (b) $602 \mathrm{~nm}$.

Figure $12 \mathrm{CIE}$ coordinates of $\mathrm{NaSrPO}_{4}: 2 \% \mathrm{Dy}^{3+}$ and $\mathrm{NaSrPO}_{4}: 2 \% \mathrm{Dy}^{3+}, y \mathrm{Sm}^{3+}$ phosphors. 
Figure 1

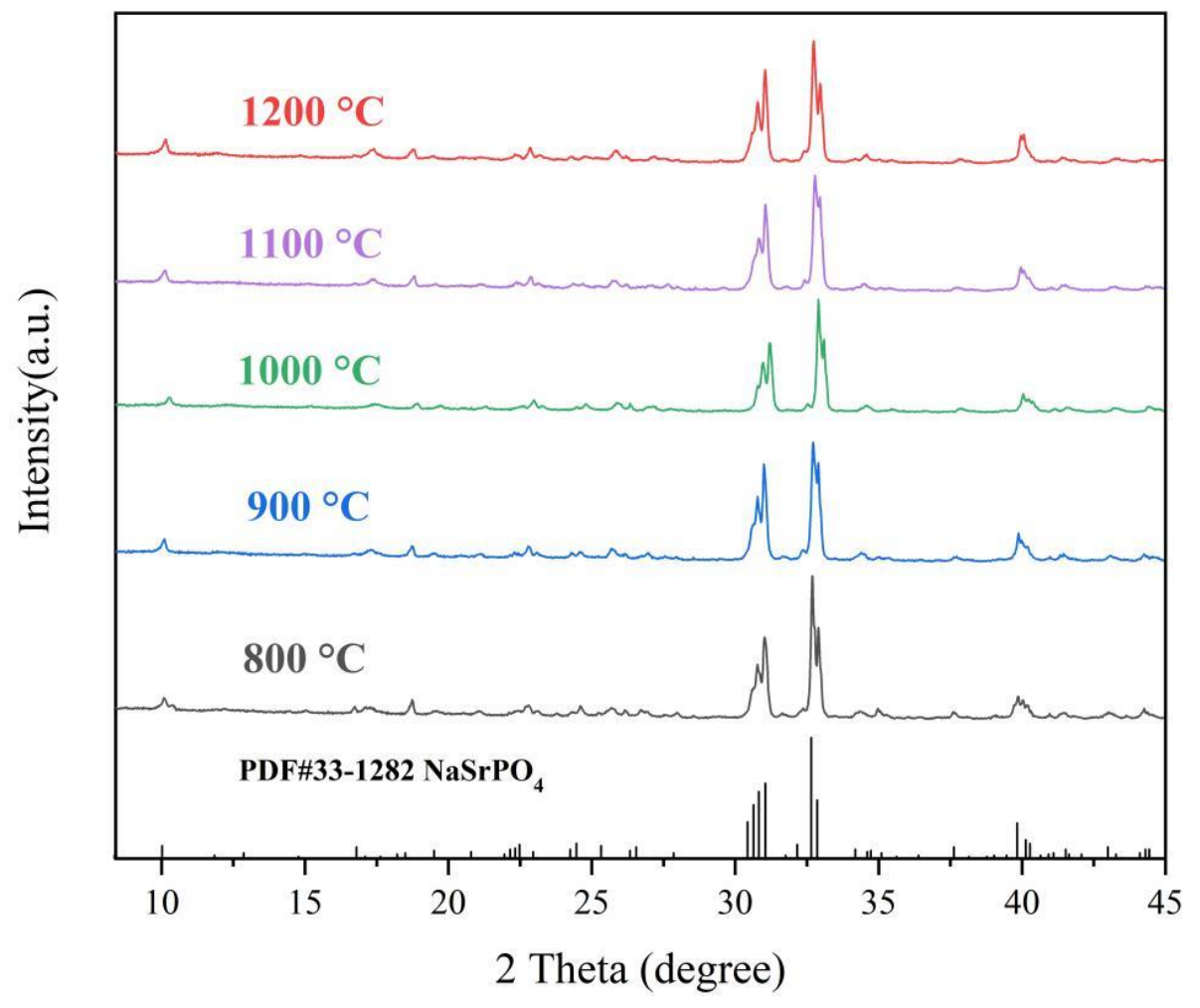


Figure 2
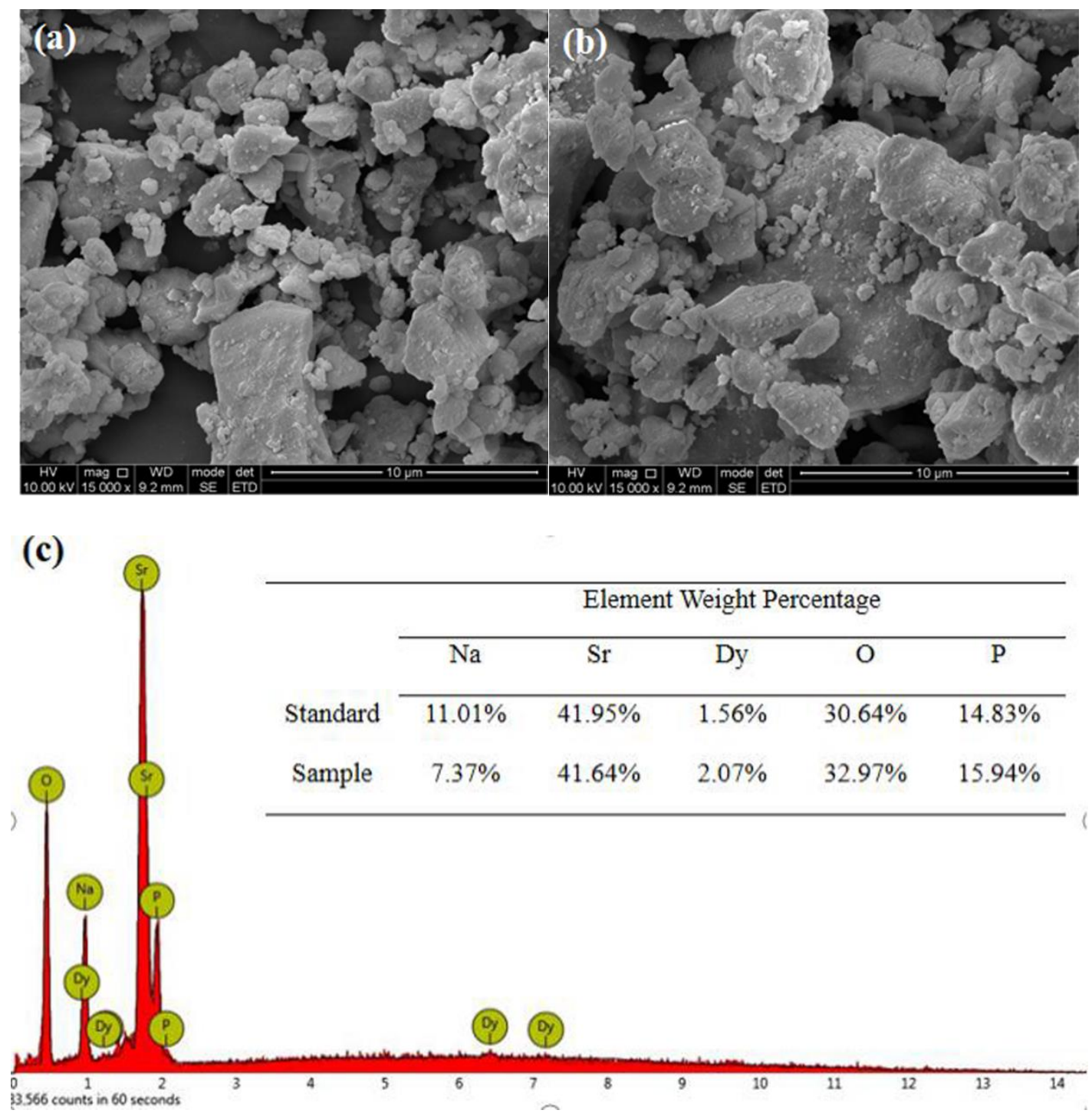
Figure 3

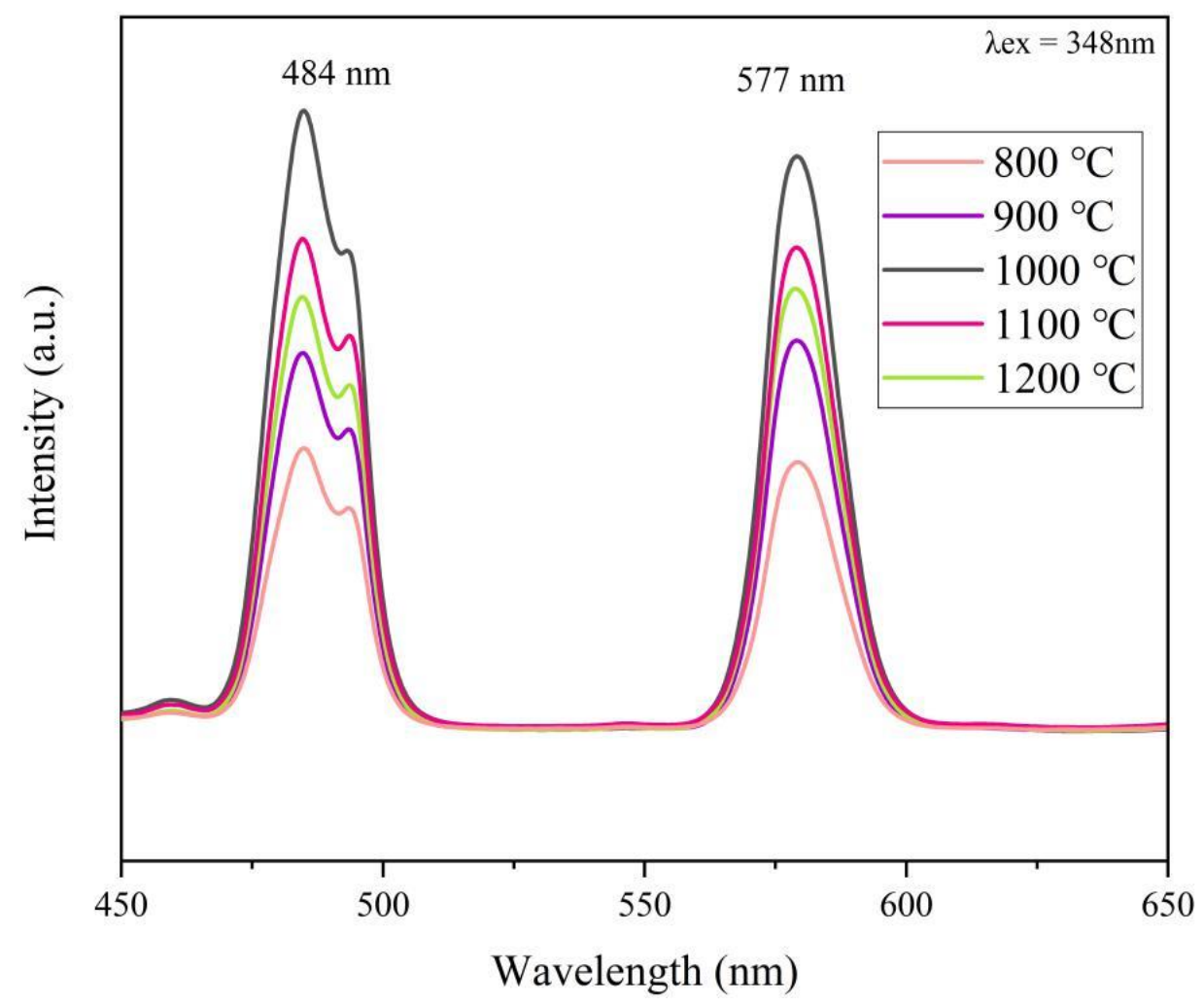


Figure 4

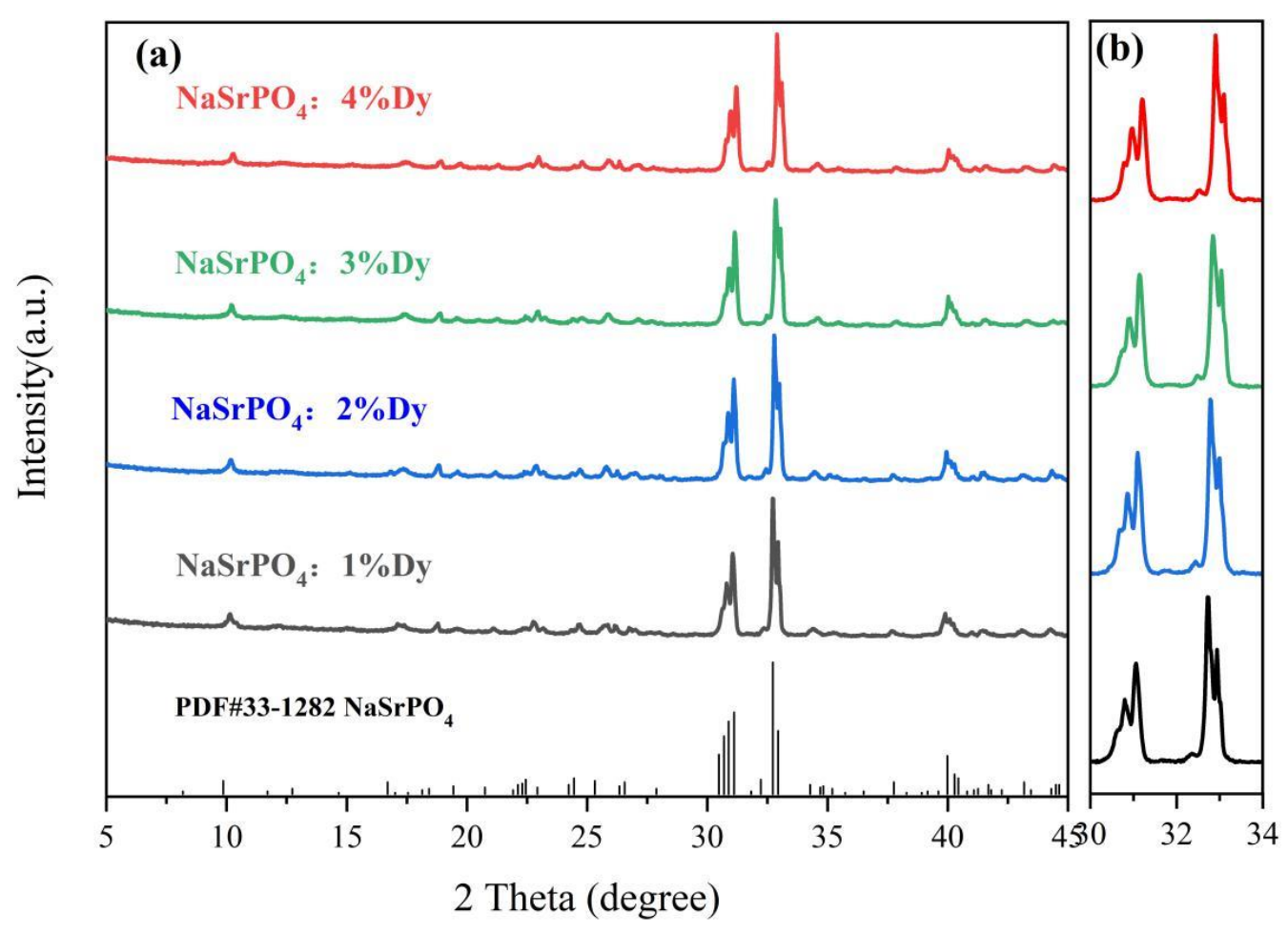


Figure 5
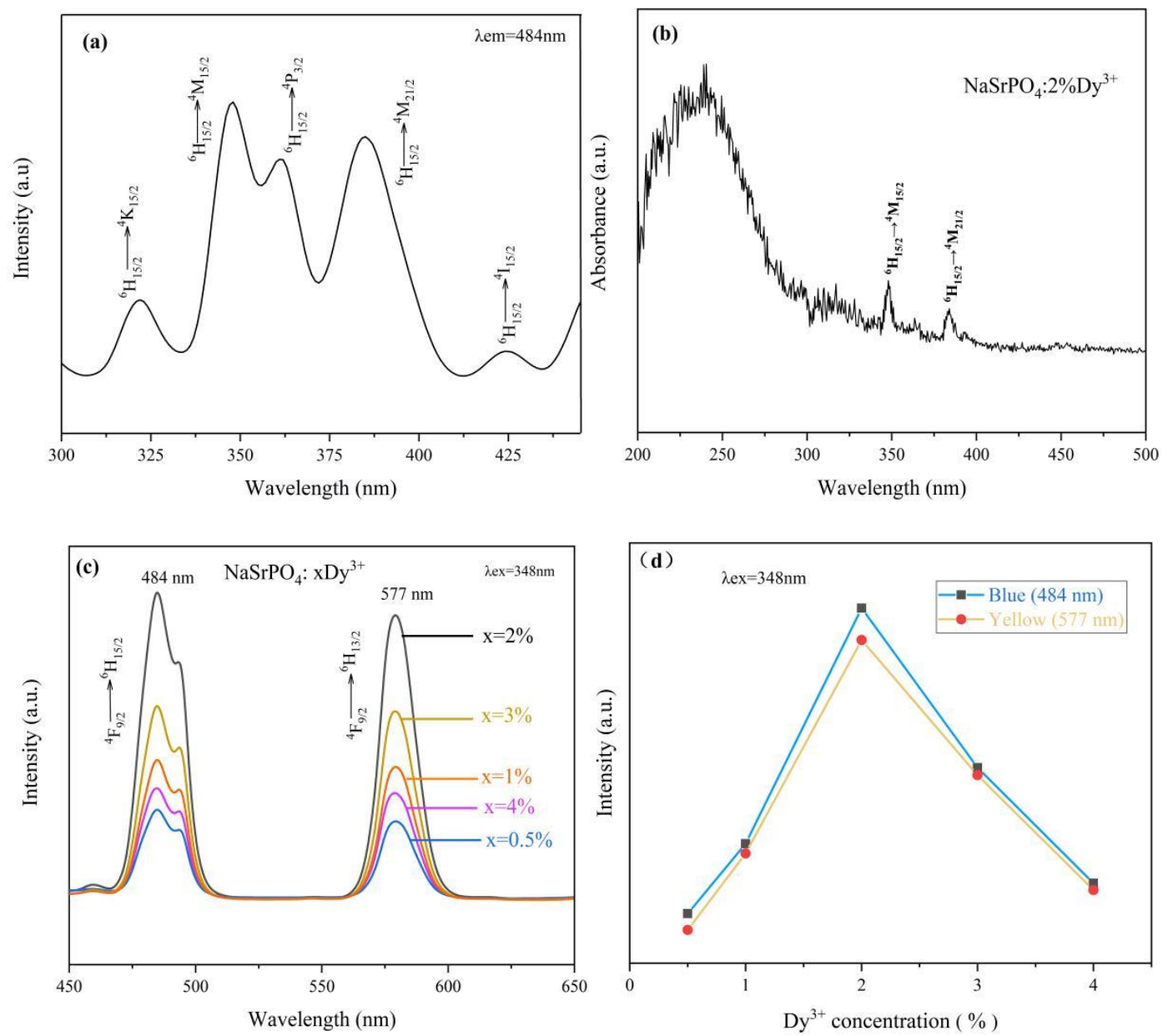
Figure 6

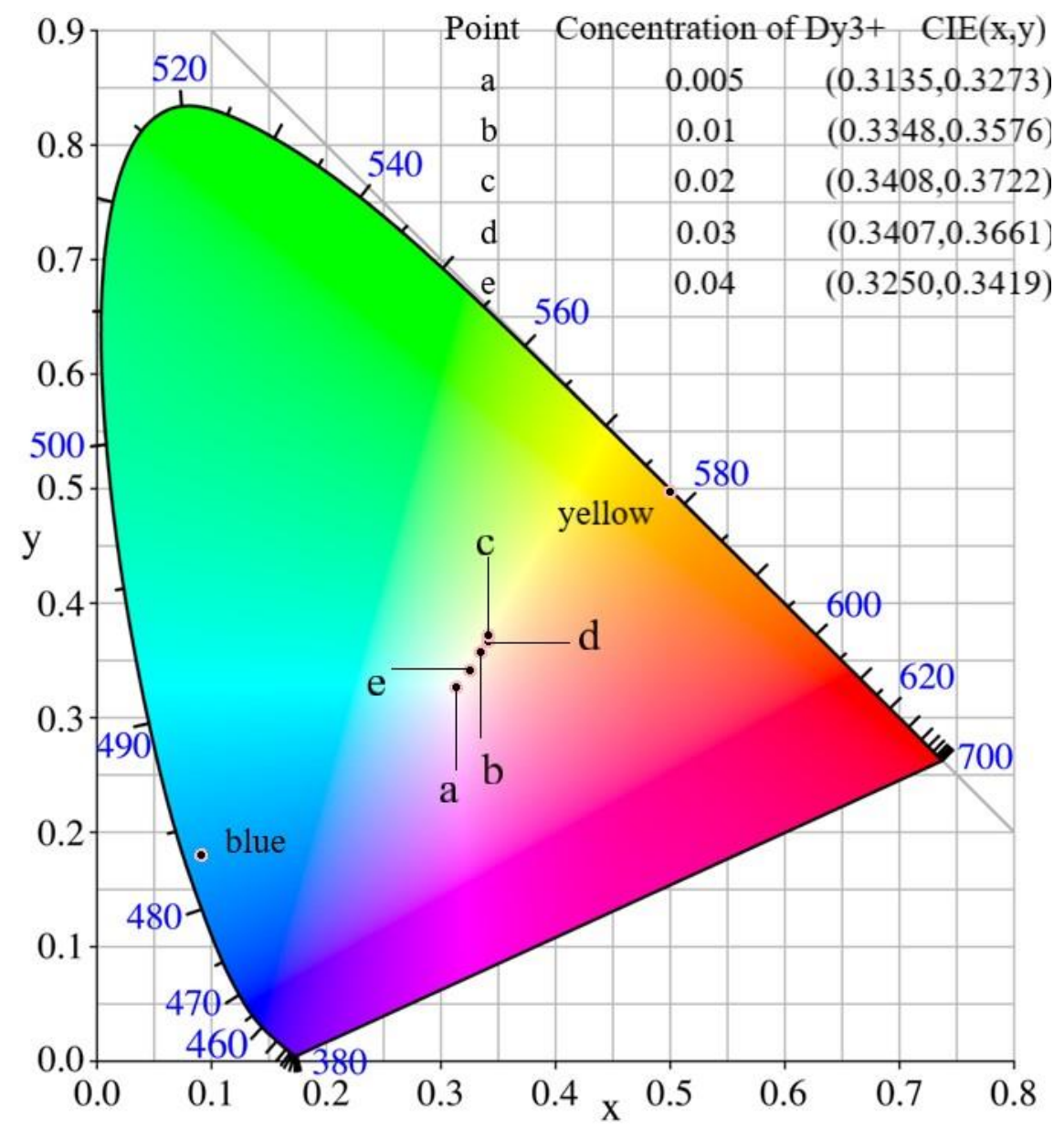


Figure 7
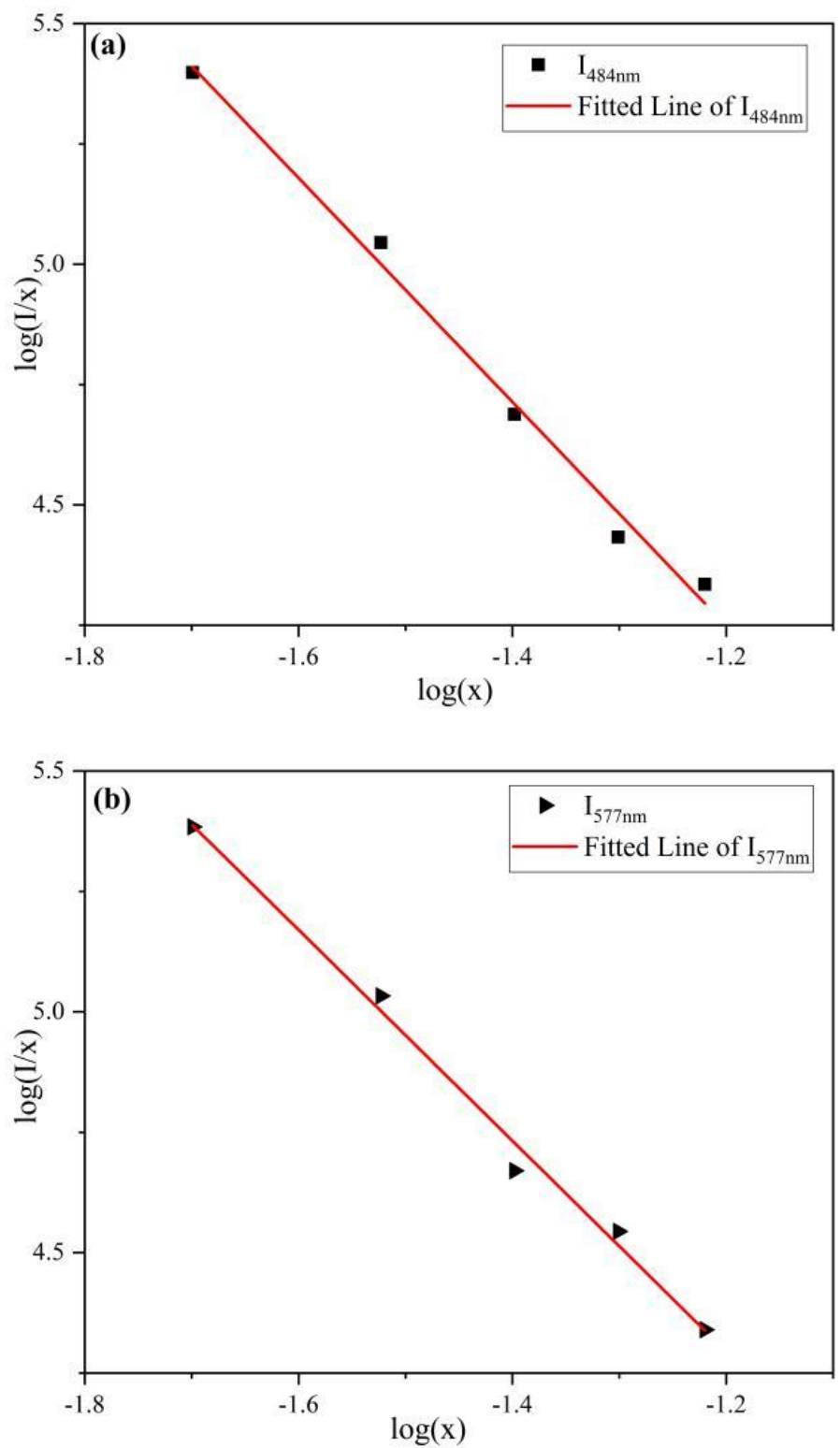
Figure 8

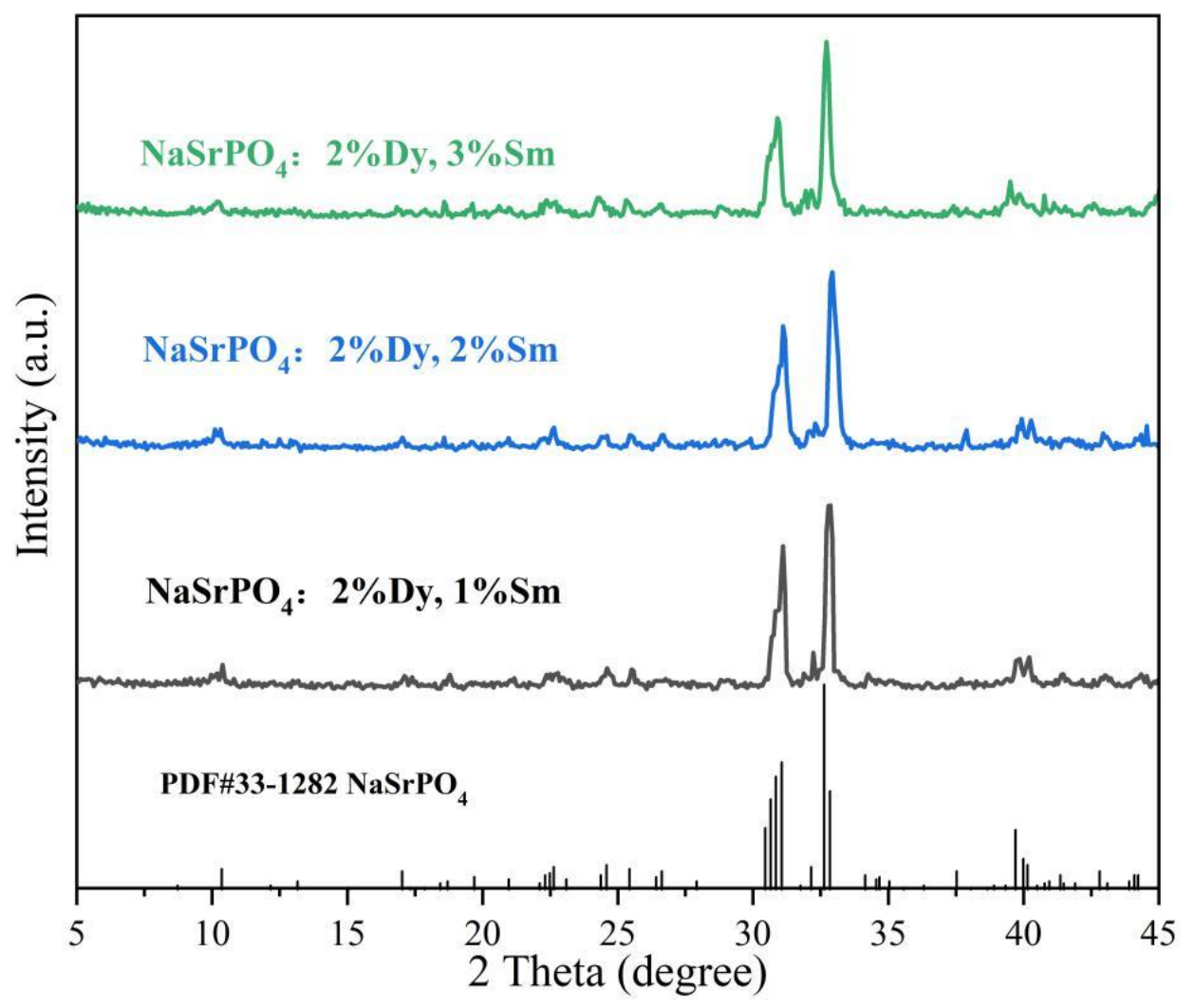


Figure 9
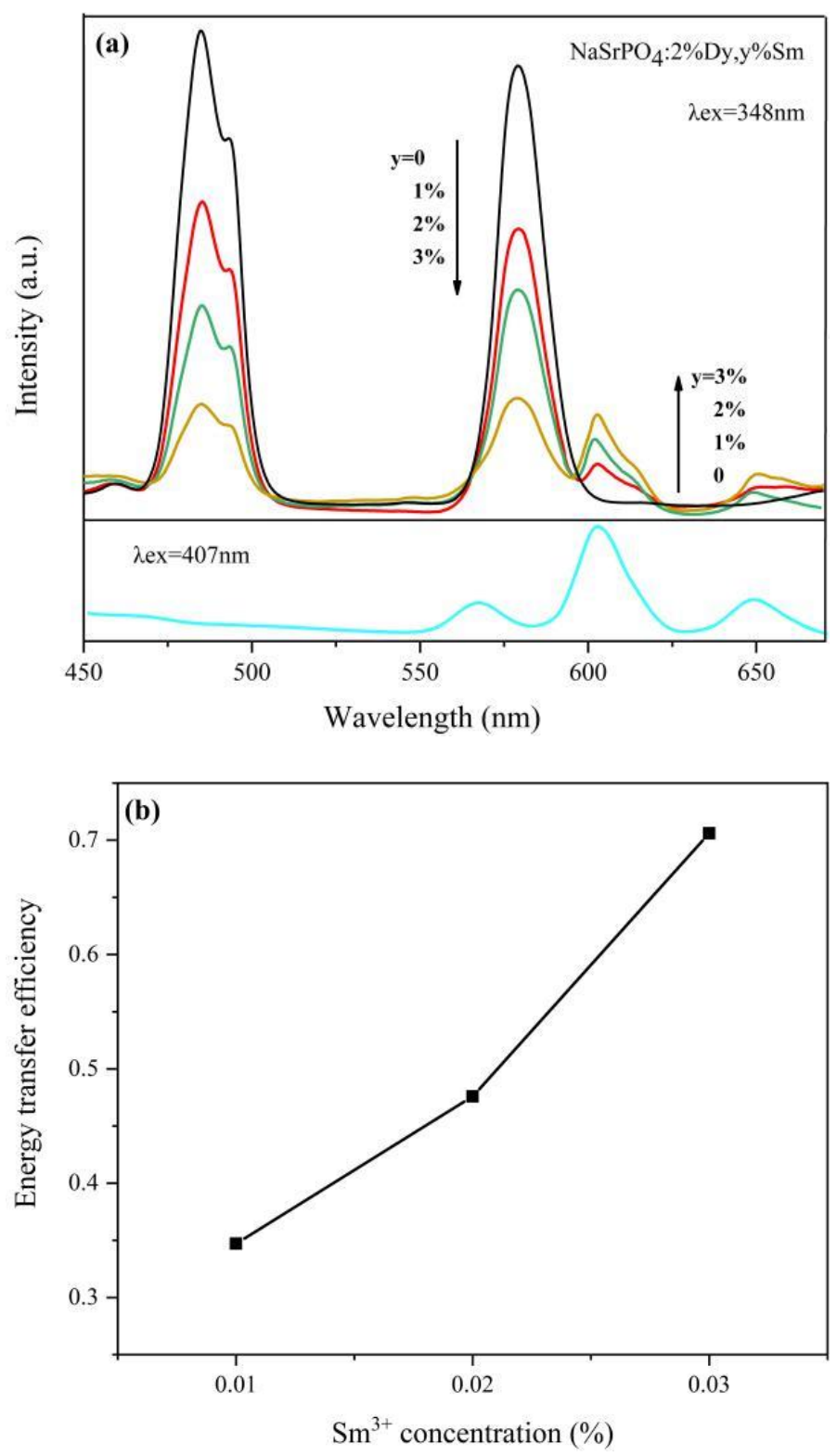
Figure 10
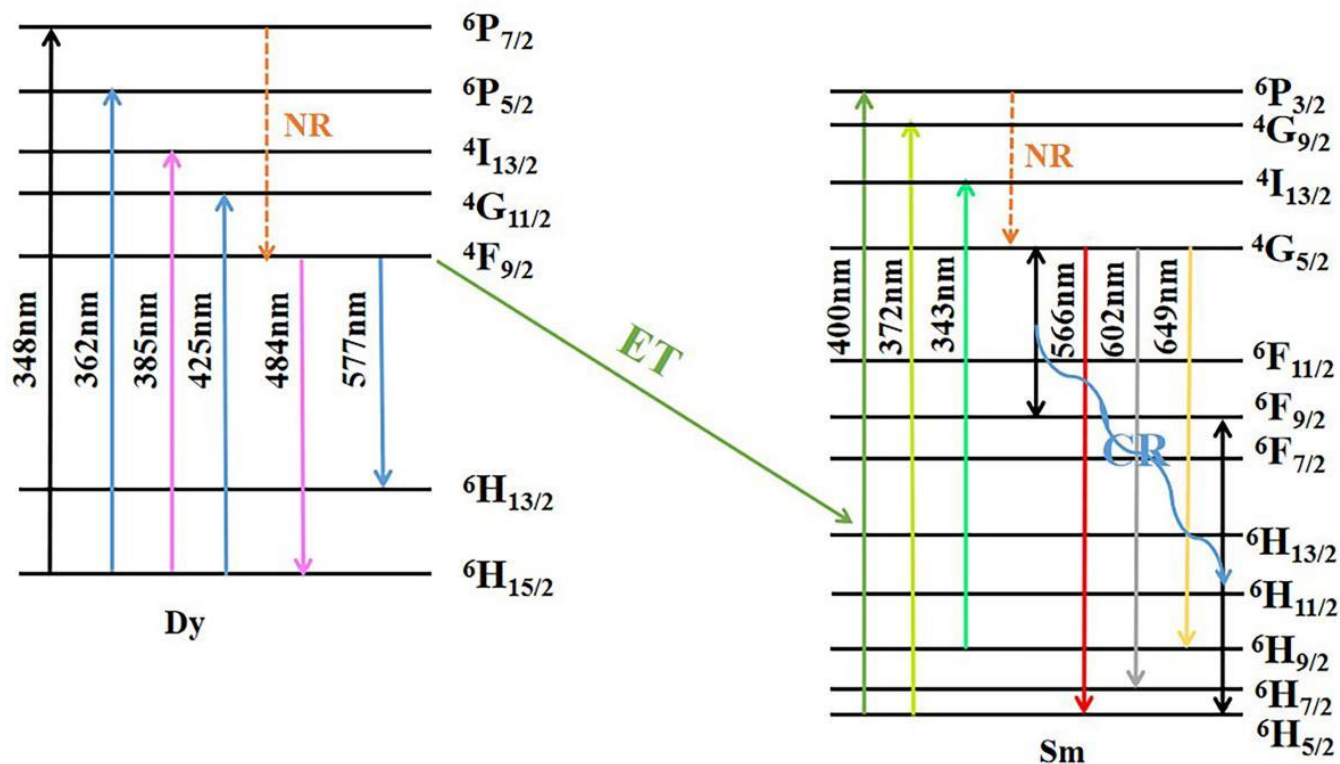
Figure 11
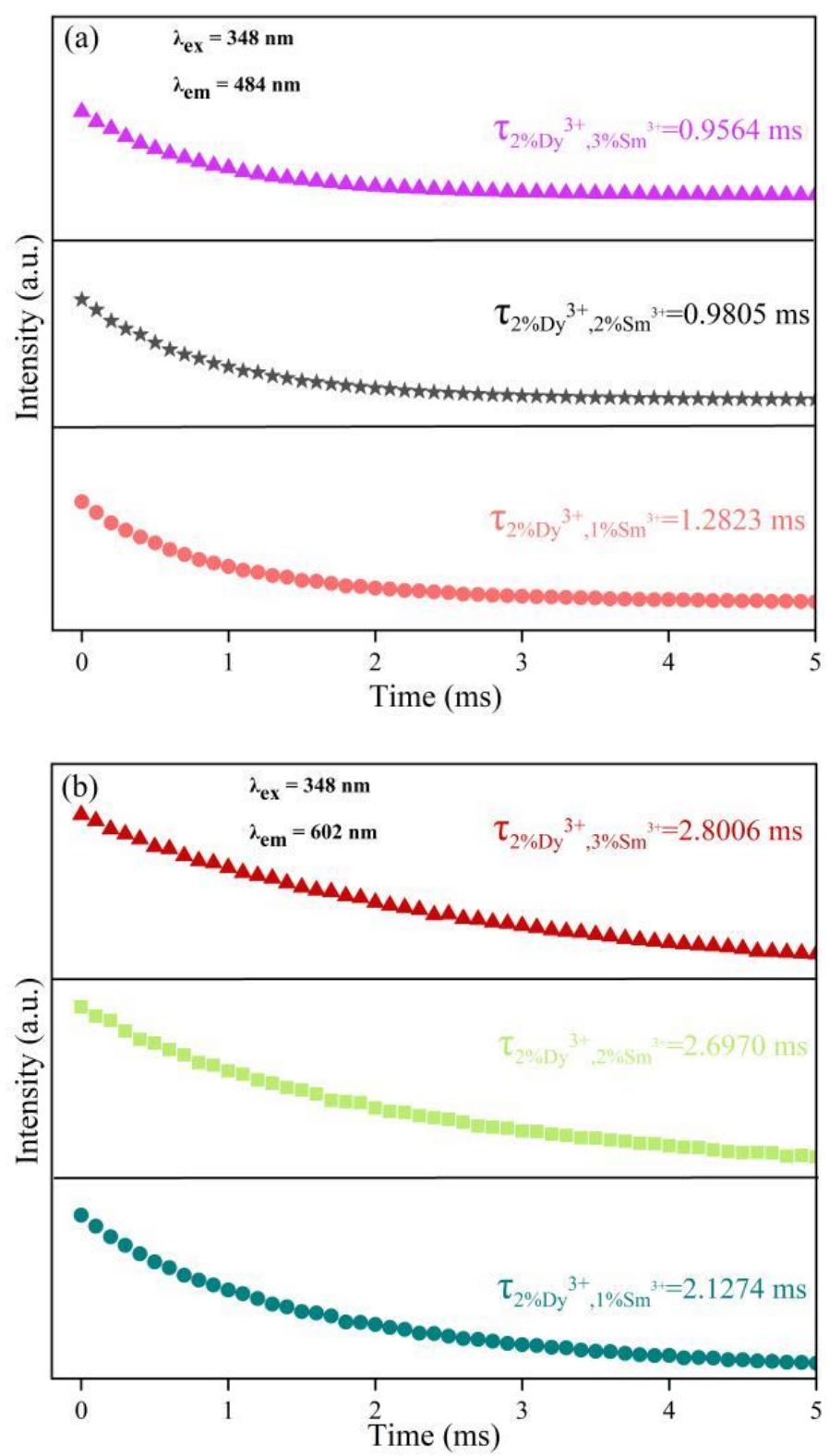
Figure 12

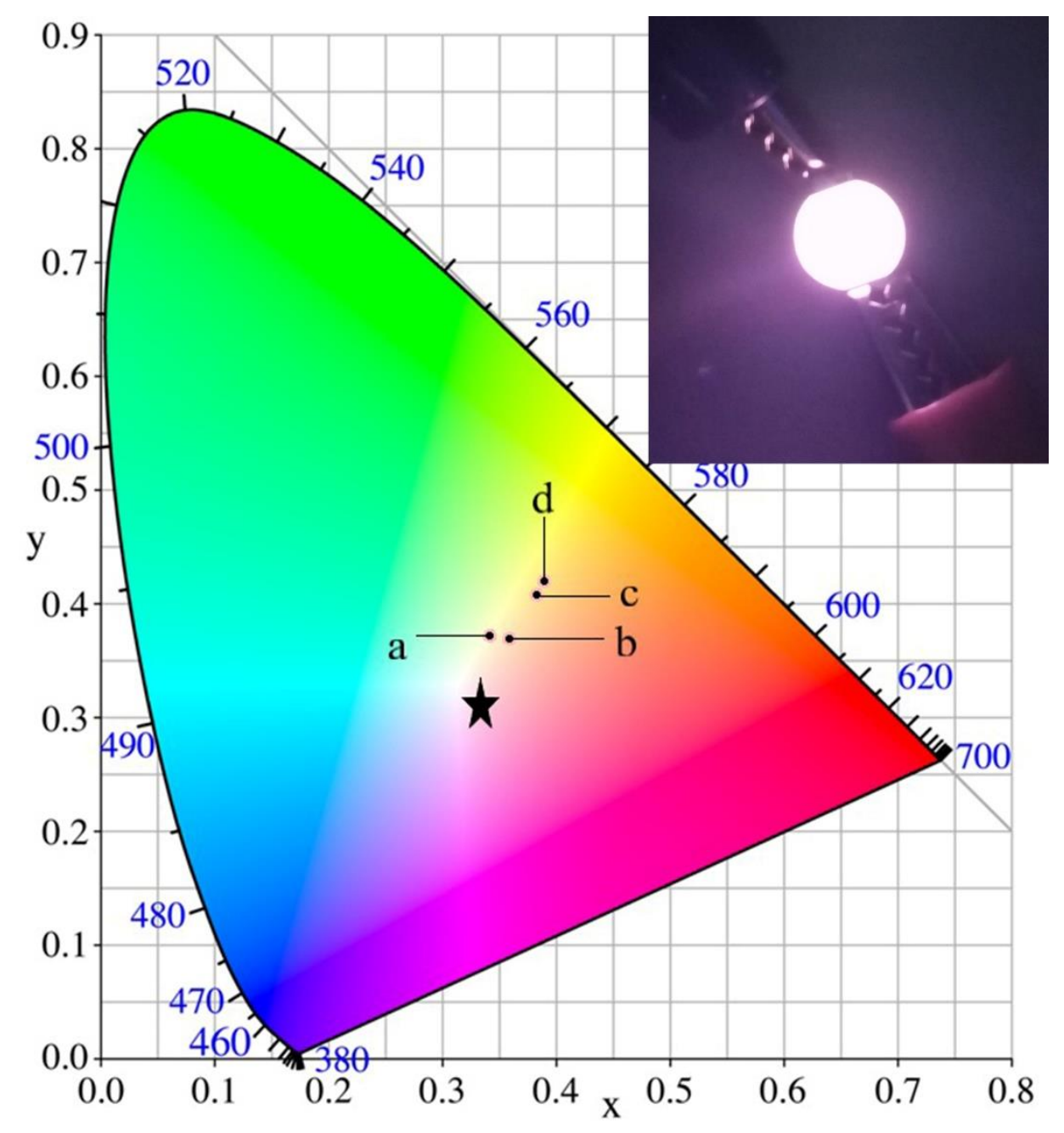


Figures

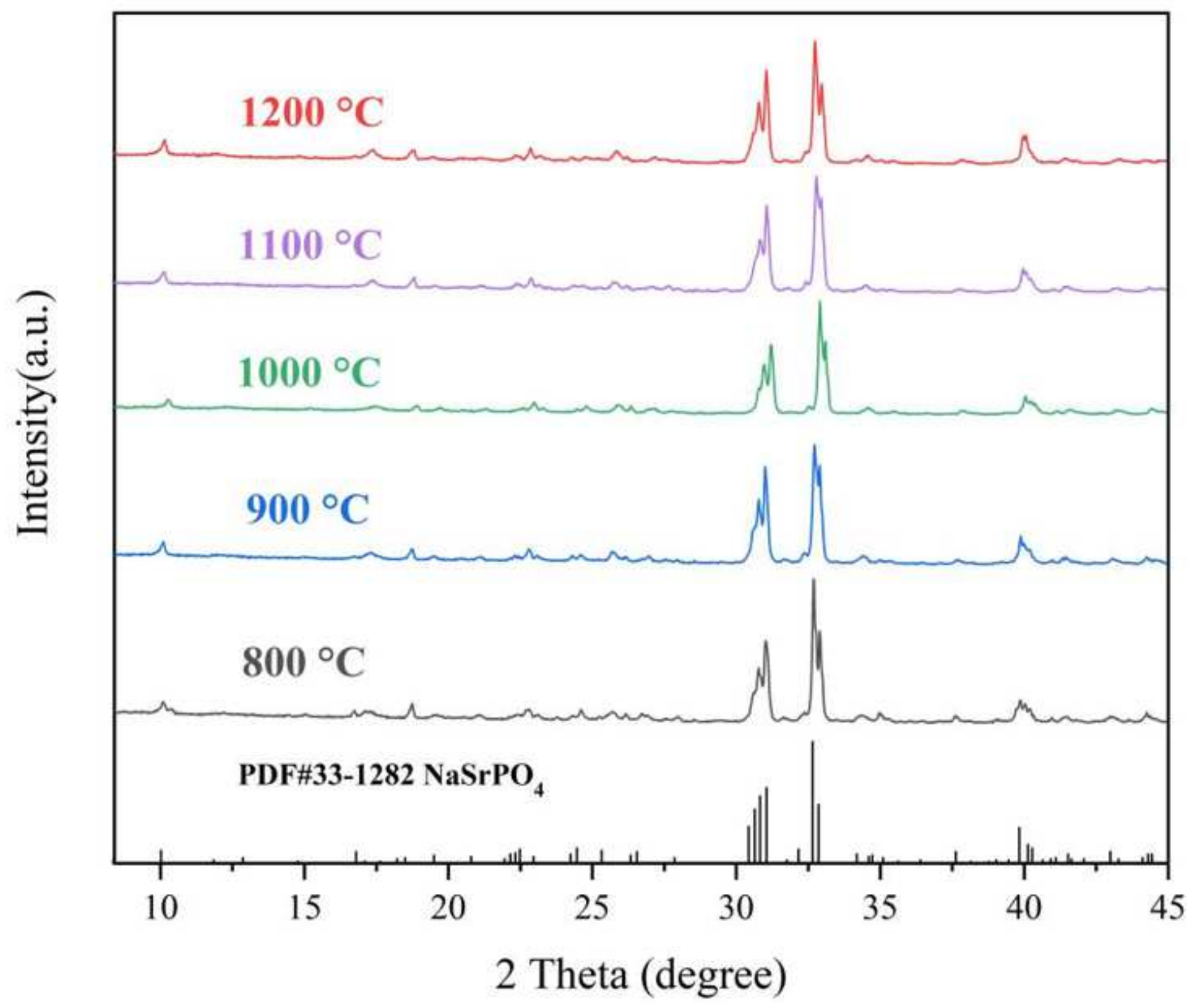

Figure 1

XRD patterns of NaSrP04:2\%Dy3+ samples prepared at various synthesis temperatures. 

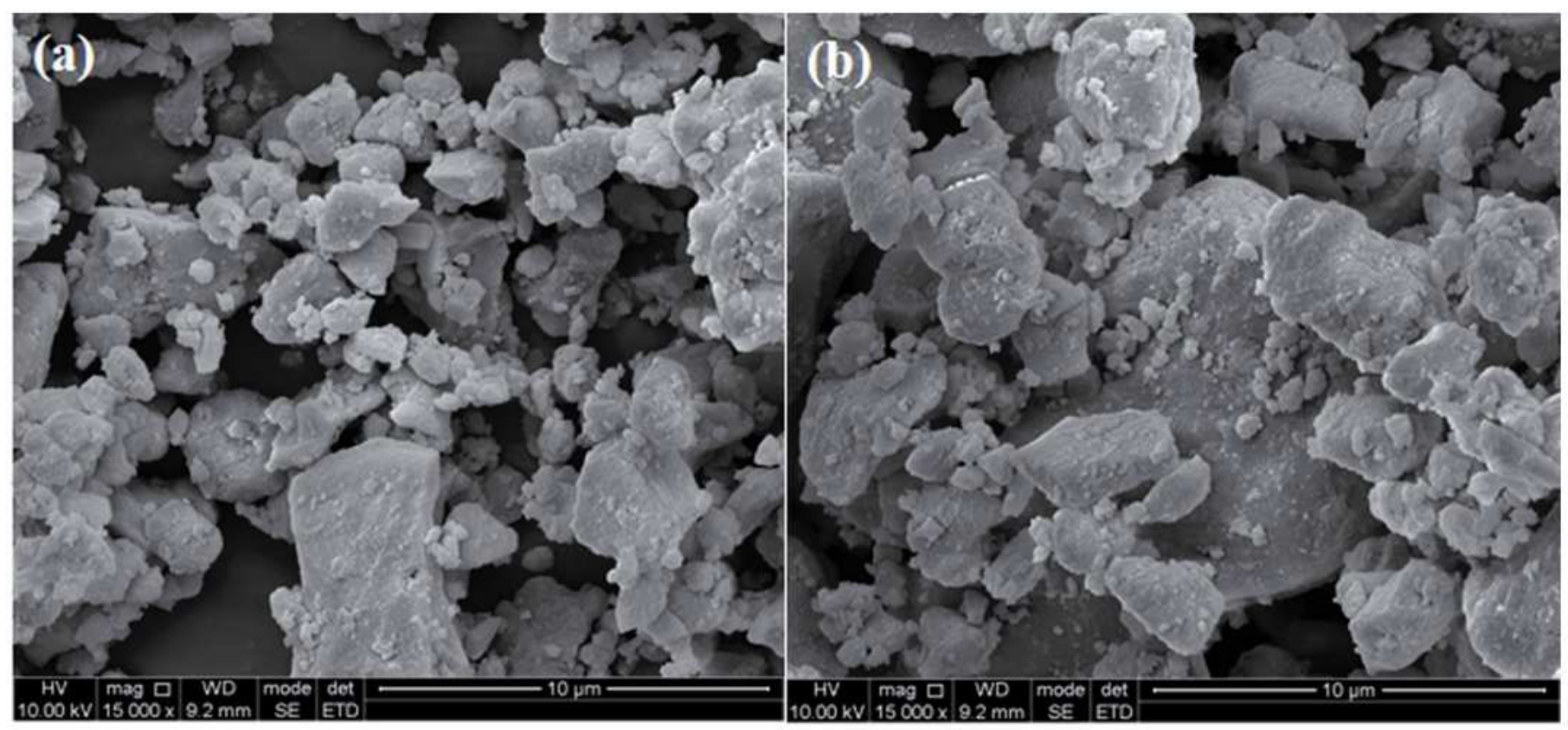

(c)

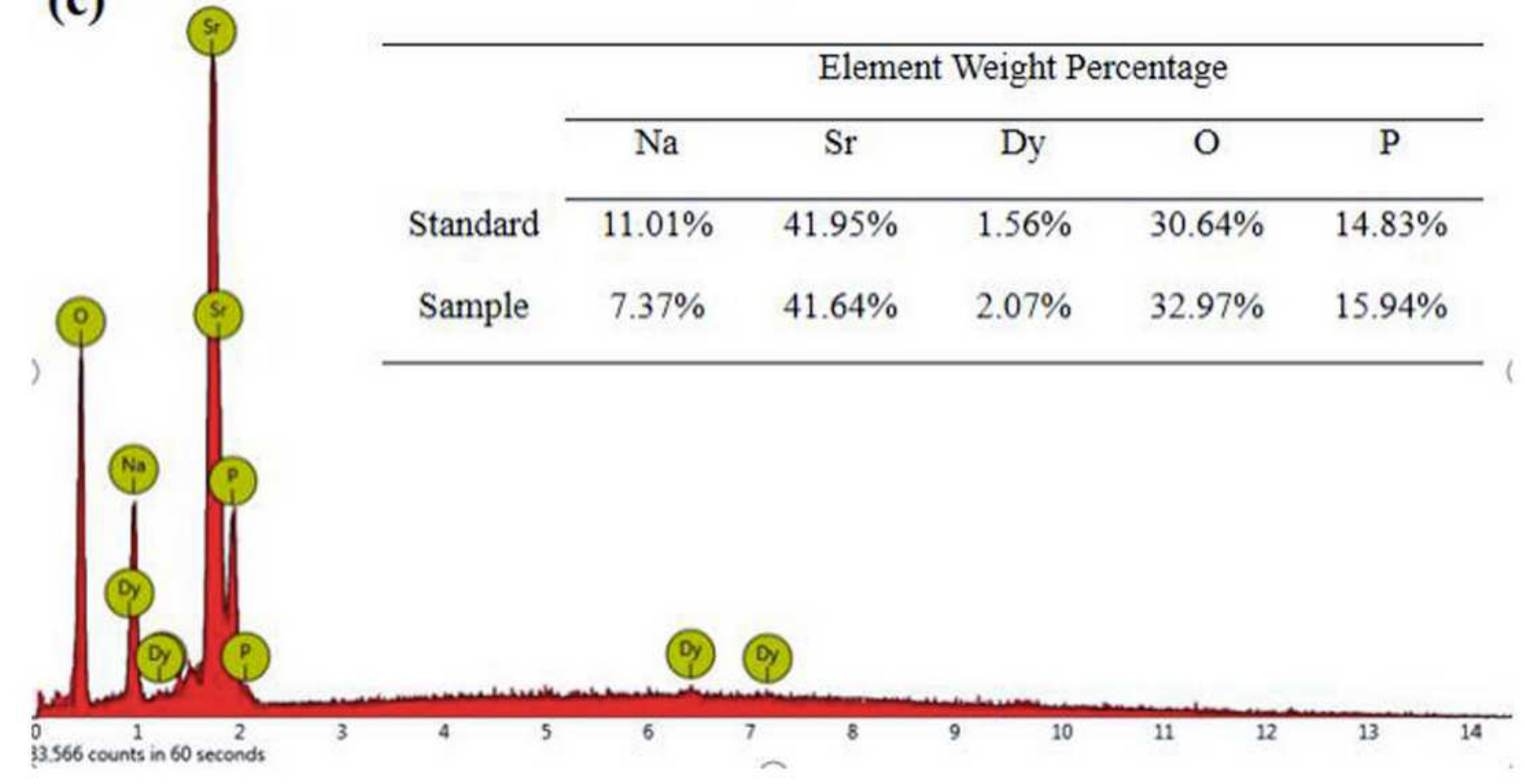

Figure 2

SEM images of $2 \%$ Dy3+-doped NaSrPO4 phosphor prepared at (a) $800{ }^{\circ} \mathrm{C}$ and (b) $1000{ }^{\circ} \mathrm{C}$ and (c) corresponding EDS results. 


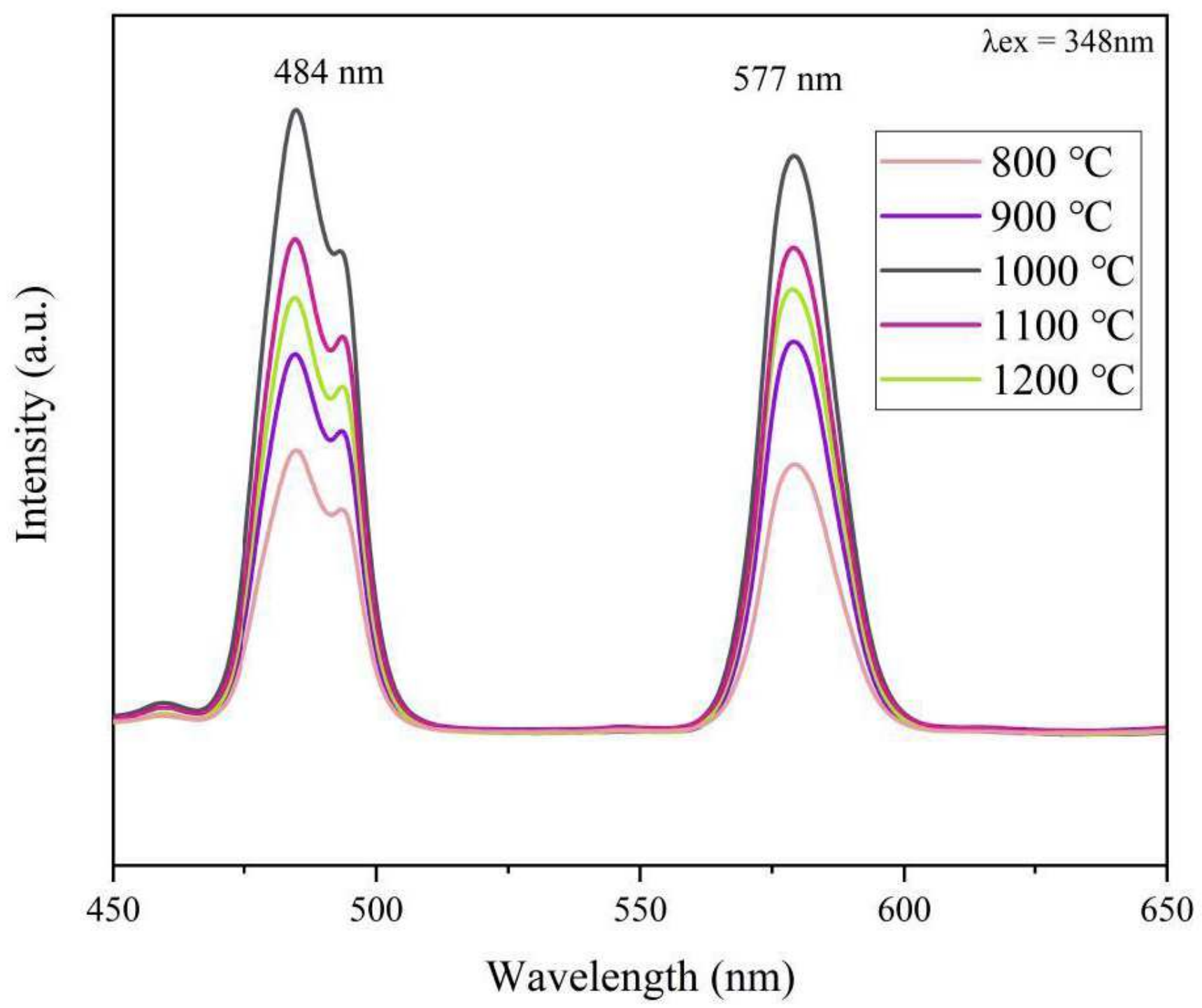

Figure 3

Emission spectra of NaSrP04:Dy3+ phosphors under excitation of $348 \mathrm{~nm}$ synthesized at specific temperatures. 


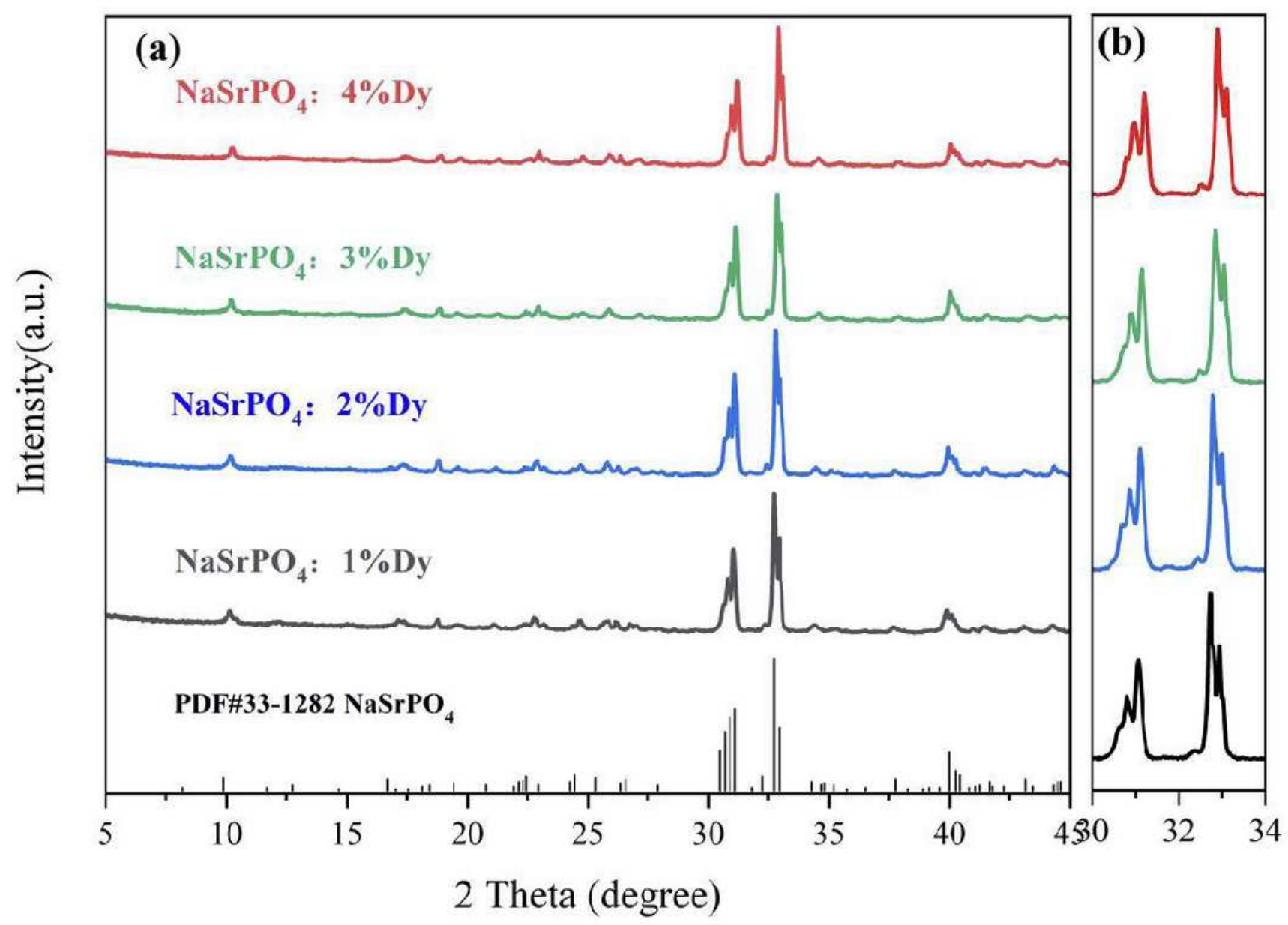

Figure 4

(a) XRD patterns of NaSrPO4: $x$ Dy3 $+(x=1 \%, 2 \%, 3 \%, 4 \%)$ with specified Dy3+ ion concentrations and (b) enlarged patterns in the $2 \theta$ ranged $30^{\circ}-34^{\circ}$. 

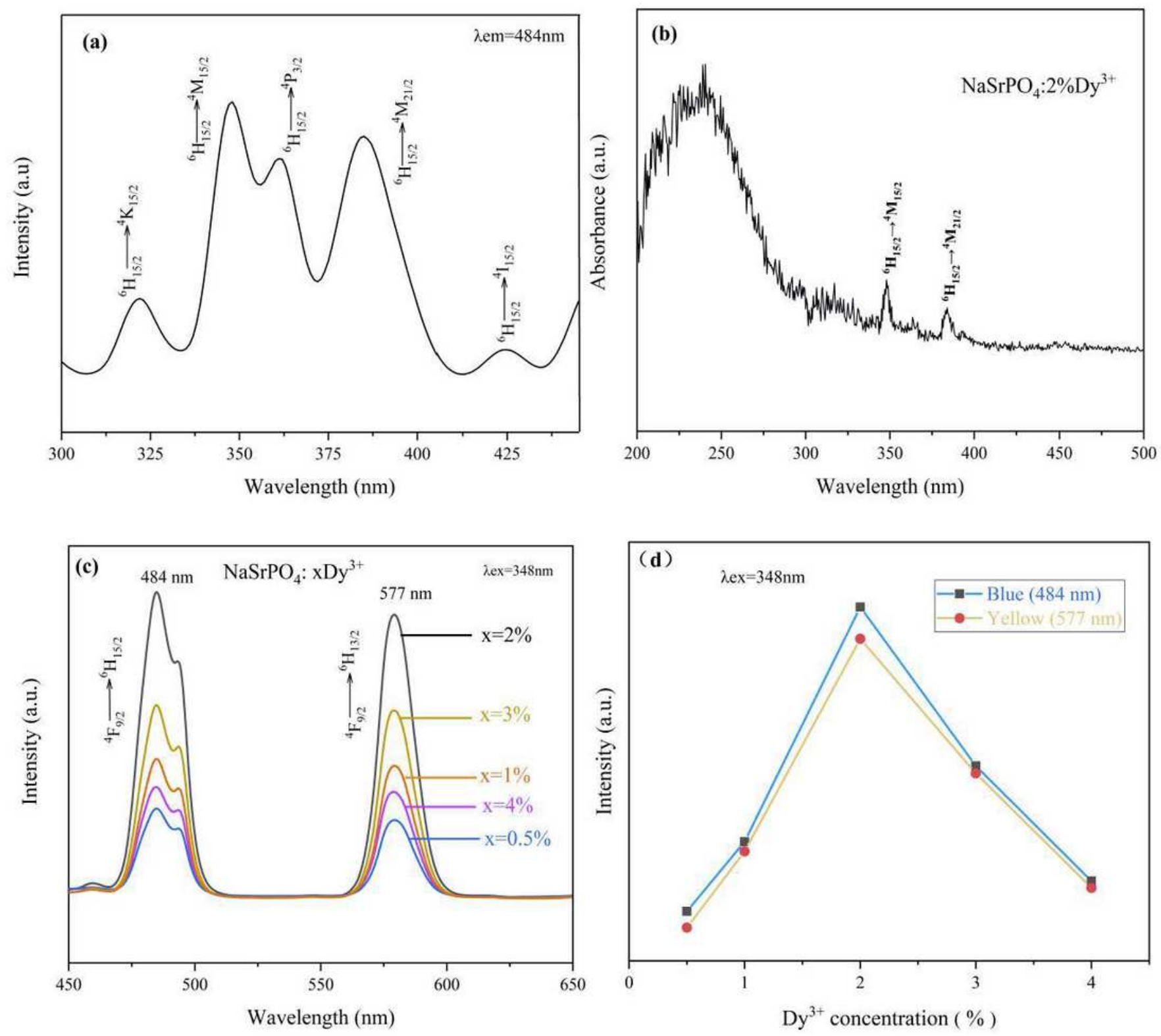

Figure 5

(a) Excitation spectrum $(\lambda e m=484 \mathrm{~nm})$ and (b) UV-vis spectrum of NaSrP04:2\%Dy3+ at 1000 ; ; (c) Emission spectra of NaSrP04:xDy3+ with different Dy3+ concentrations; (d) Relevance of the luminescence intensities of two corresponding peaks (blue and yellow) on Dy3+ doping concentration. 


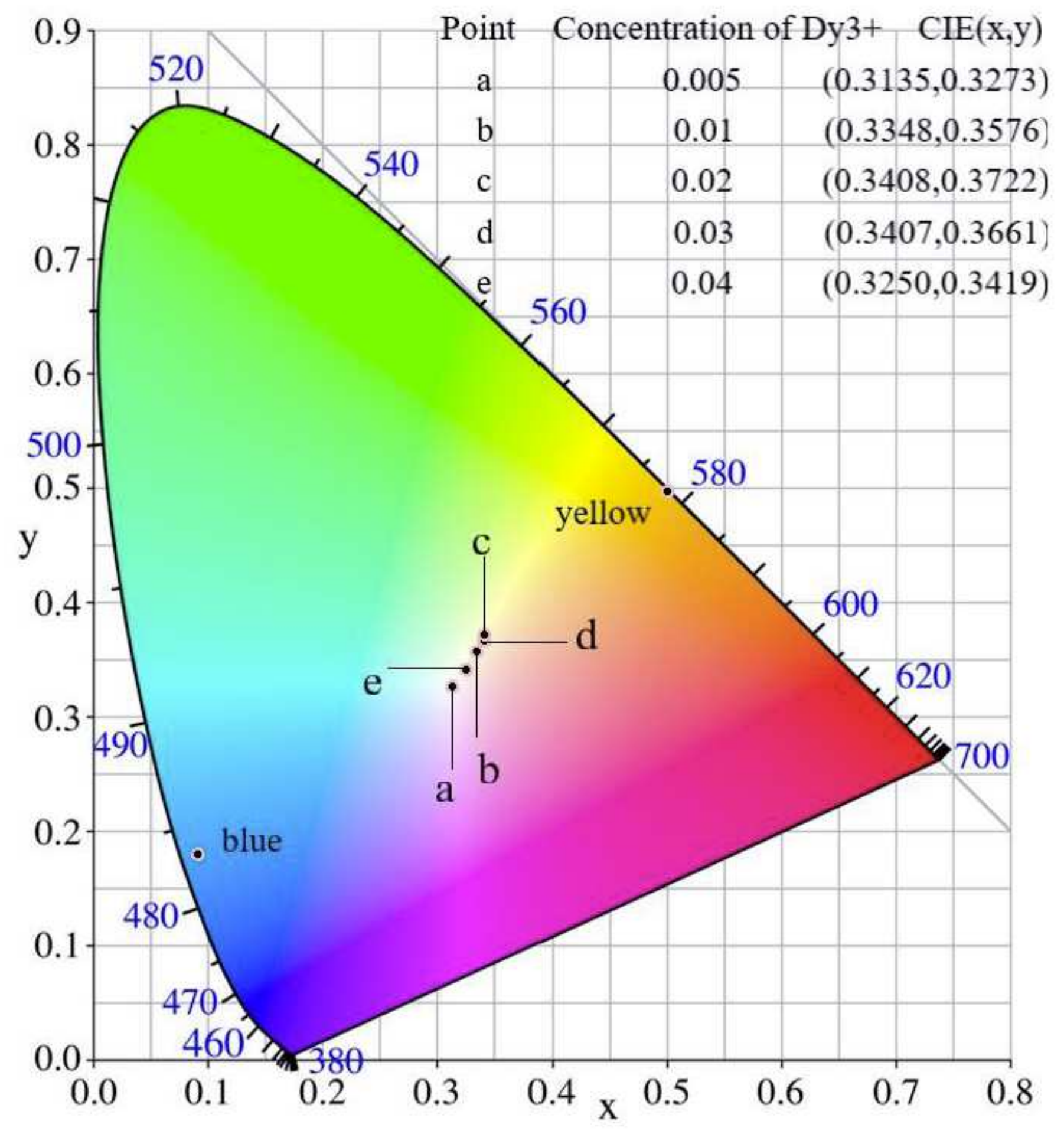

Figure 6

CIE coordinates of NaSrPO4:xDy3+ with specified Dy3+ ion concentrations. 

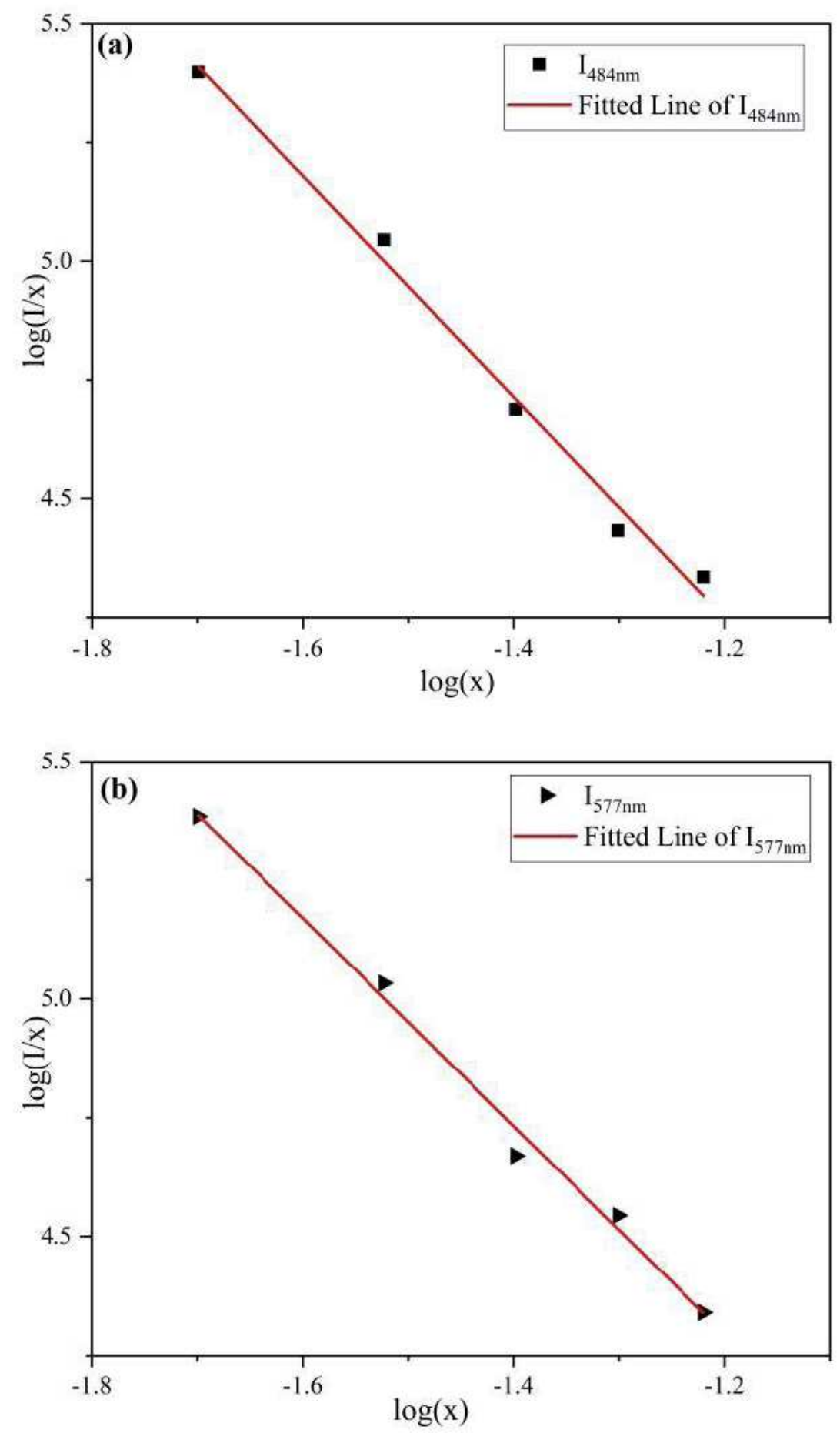

Figure 7

(a) Fitting results of $\log (\mathrm{I} / \mathrm{x})$ and $\log (\mathrm{x})$ for the $4 \mathrm{~F} 9 / 2 \varangle 6 \mathrm{H} 15 / 2(484 \mathrm{~nm})$ and (b) 4F9/2 $66 \mathrm{H} 13 / 2(577 \mathrm{~nm})$ transitions of Dy3+ ions in NaSrPO4:Dy3+ phosphors. 


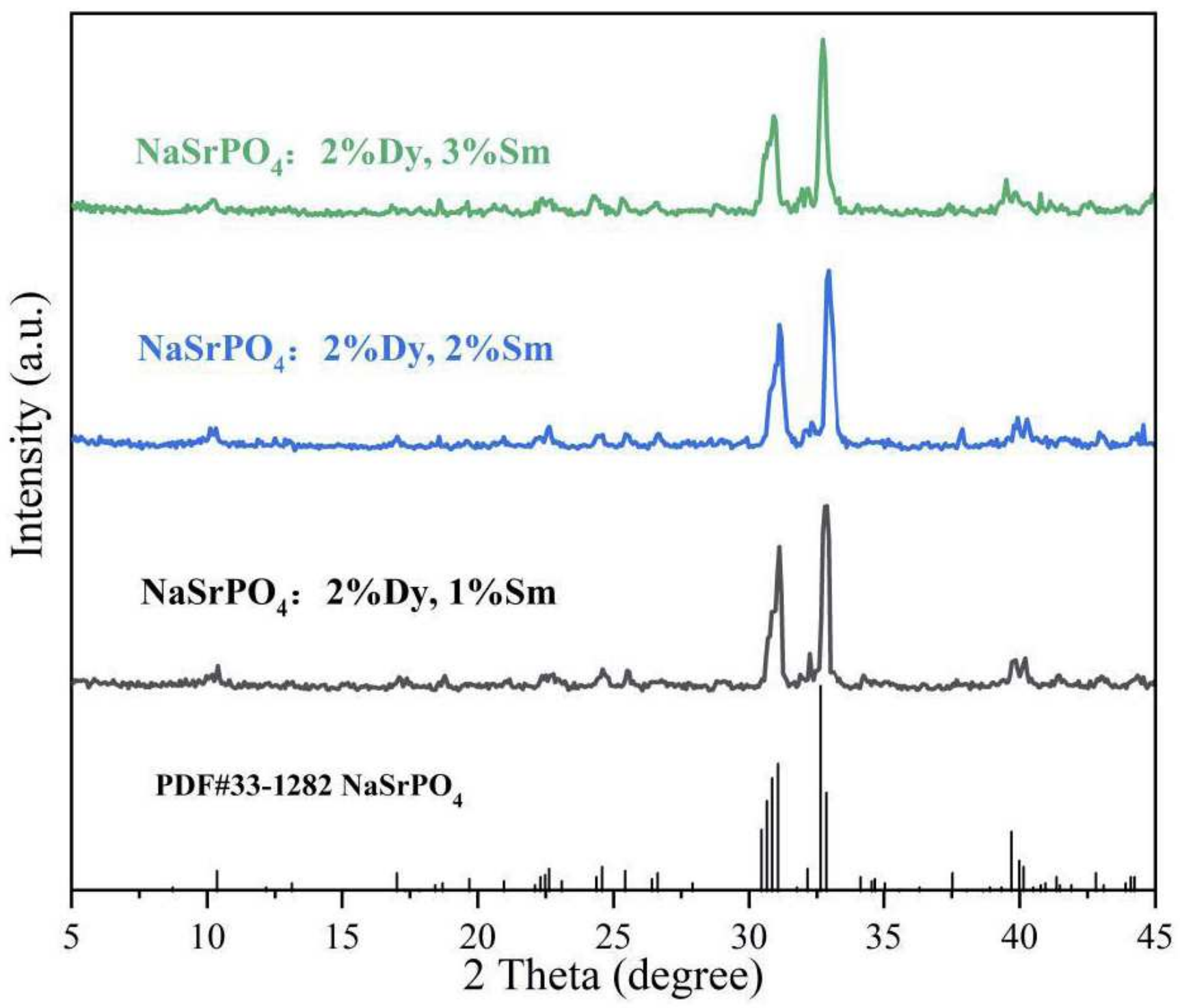

Figure 8

XRD patterns of NaSrPO4:2\% Dy3+, ySm3+ $(y=1 \%, 2 \%, 3 \%)$ with specified Sm3+ ion concentrations. 

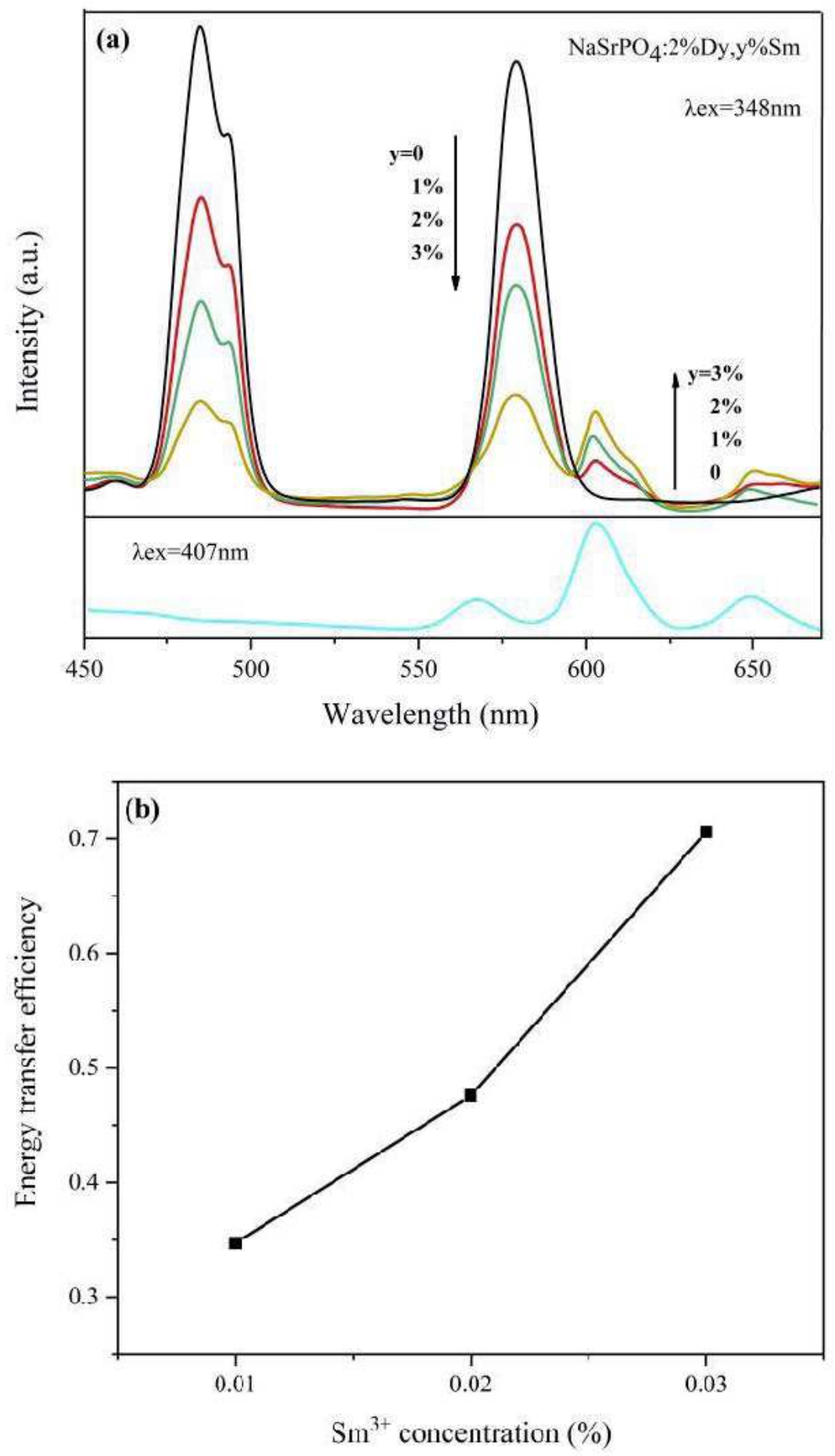

Figure 9

(a) Emission spectra of NaSrPO4:2\% Dy3+, ySm3+ with specified Sm3+ ion concentrations and (b) corresponding energy transfer efficiency from Dy3+ to $\mathrm{Sm} 3+$ in $\mathrm{NaSrPO} 4$ structure. 


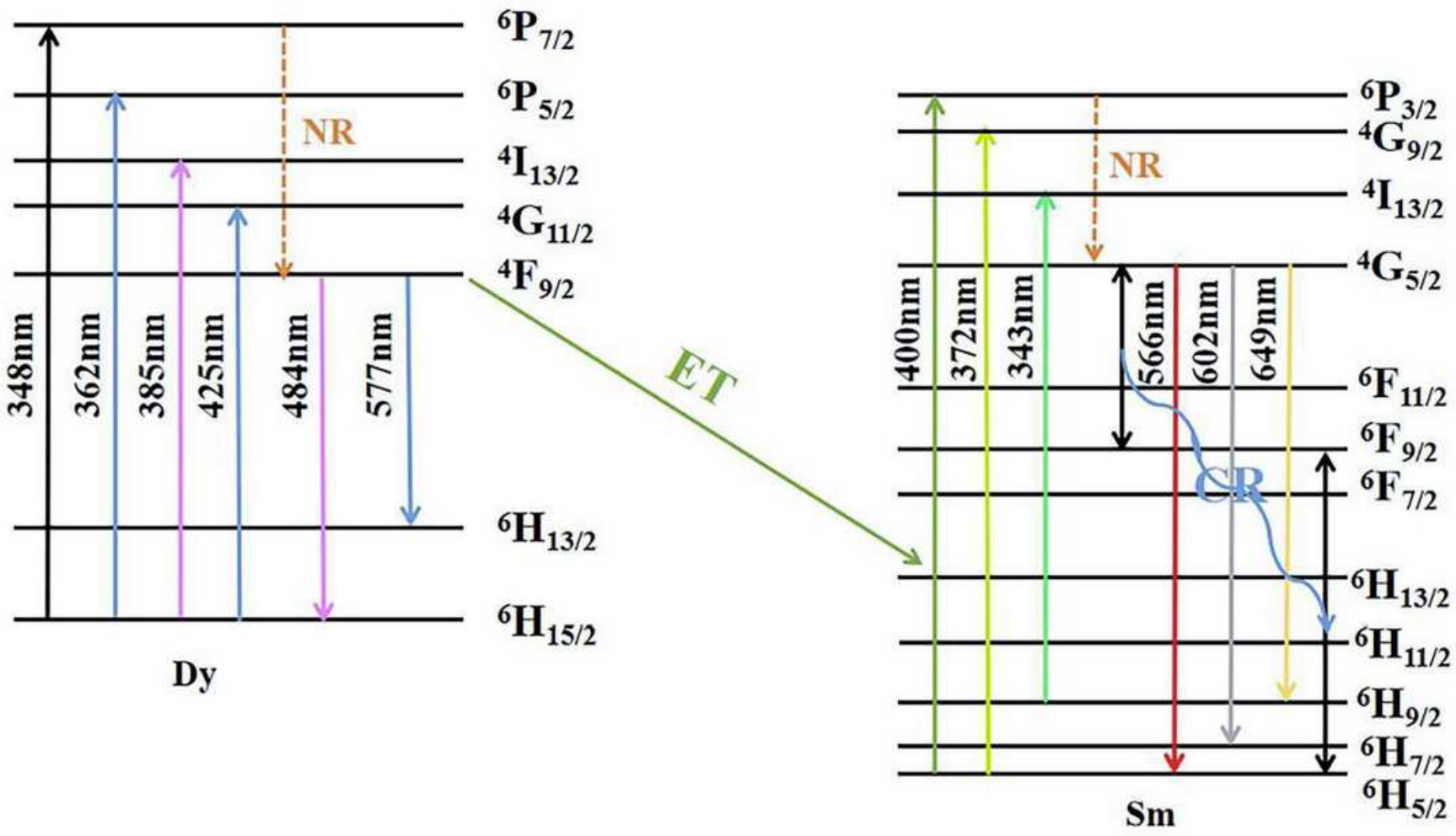

Figure 10

Schematic diagram of energy transfer from Dy3+ to Sm3+ in NaSrPO4:Dy3+, Sm3+ phosphor. 

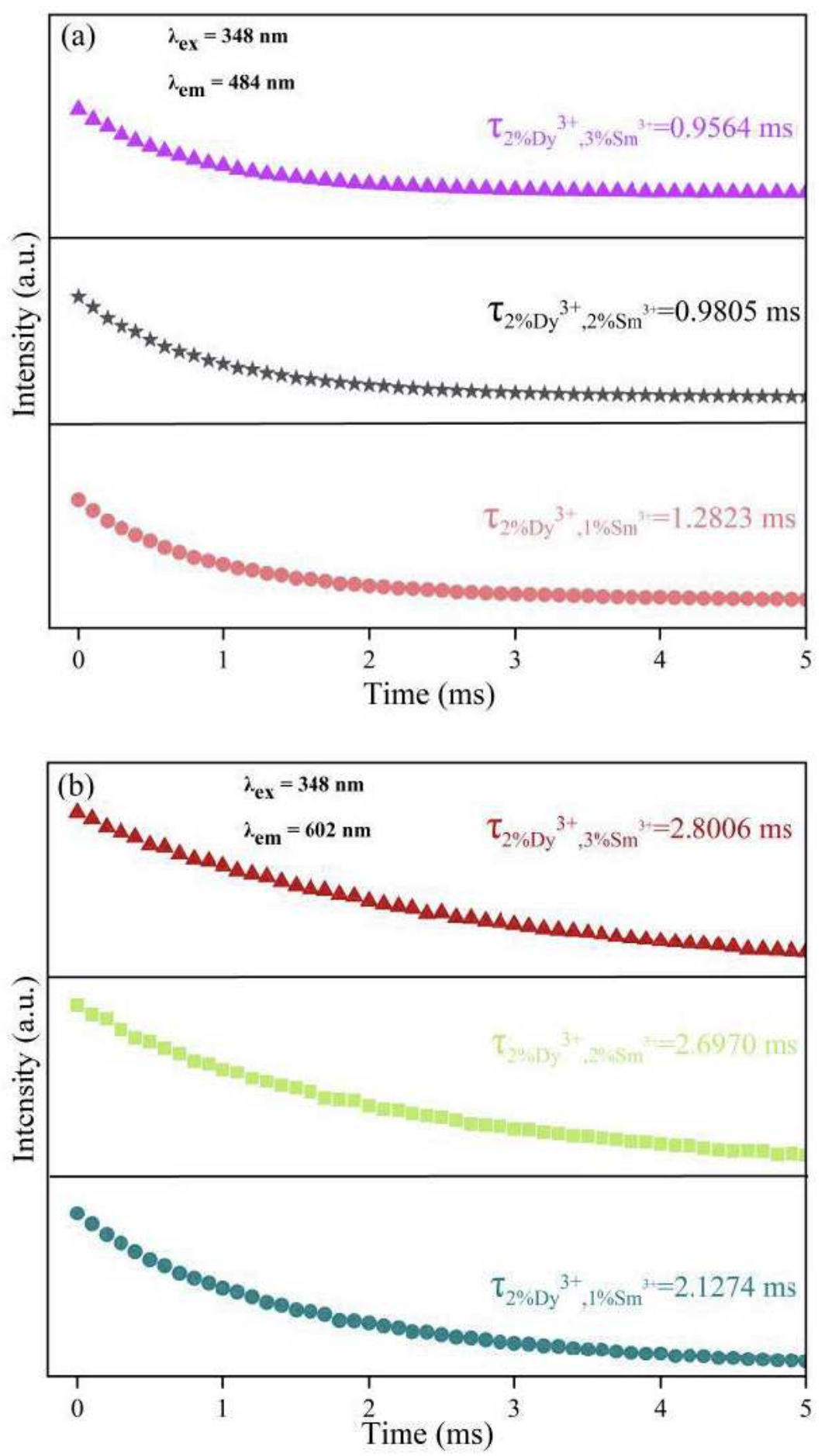

\section{Figure 11}

Decay curves of NaSrP04:2\%Dy3+, ySm3+ (y = 1\%, 2\%, and 3\%) phosphors inspected at (a) $484 \mathrm{~nm}$ and (b) $602 \mathrm{~nm}$. 


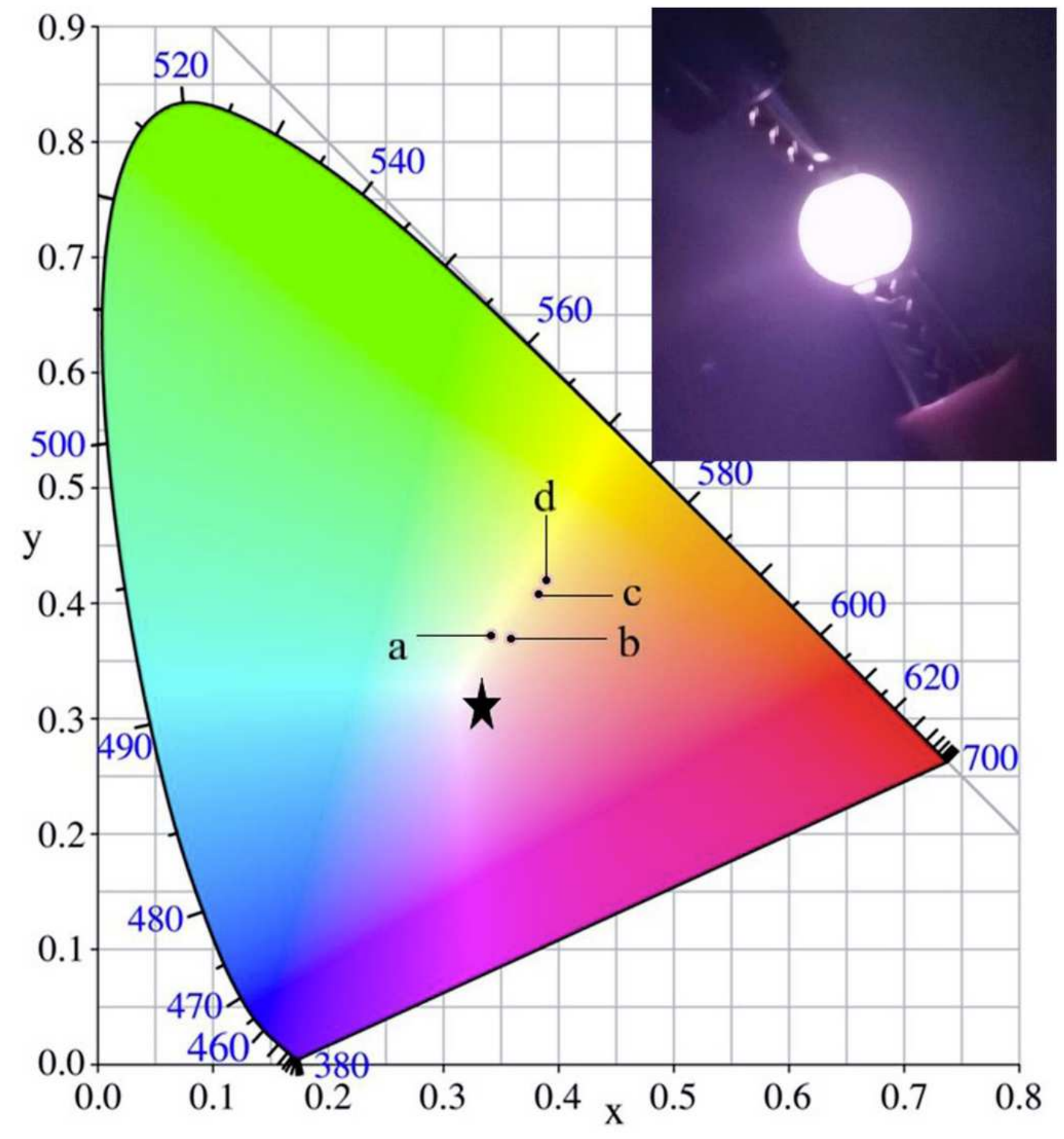

Figure 12

CIE coordinates of NaSrP04:2\%Dy3+ and NaSrPO4:2\%Dy3+, ySm3+ phosphors. 